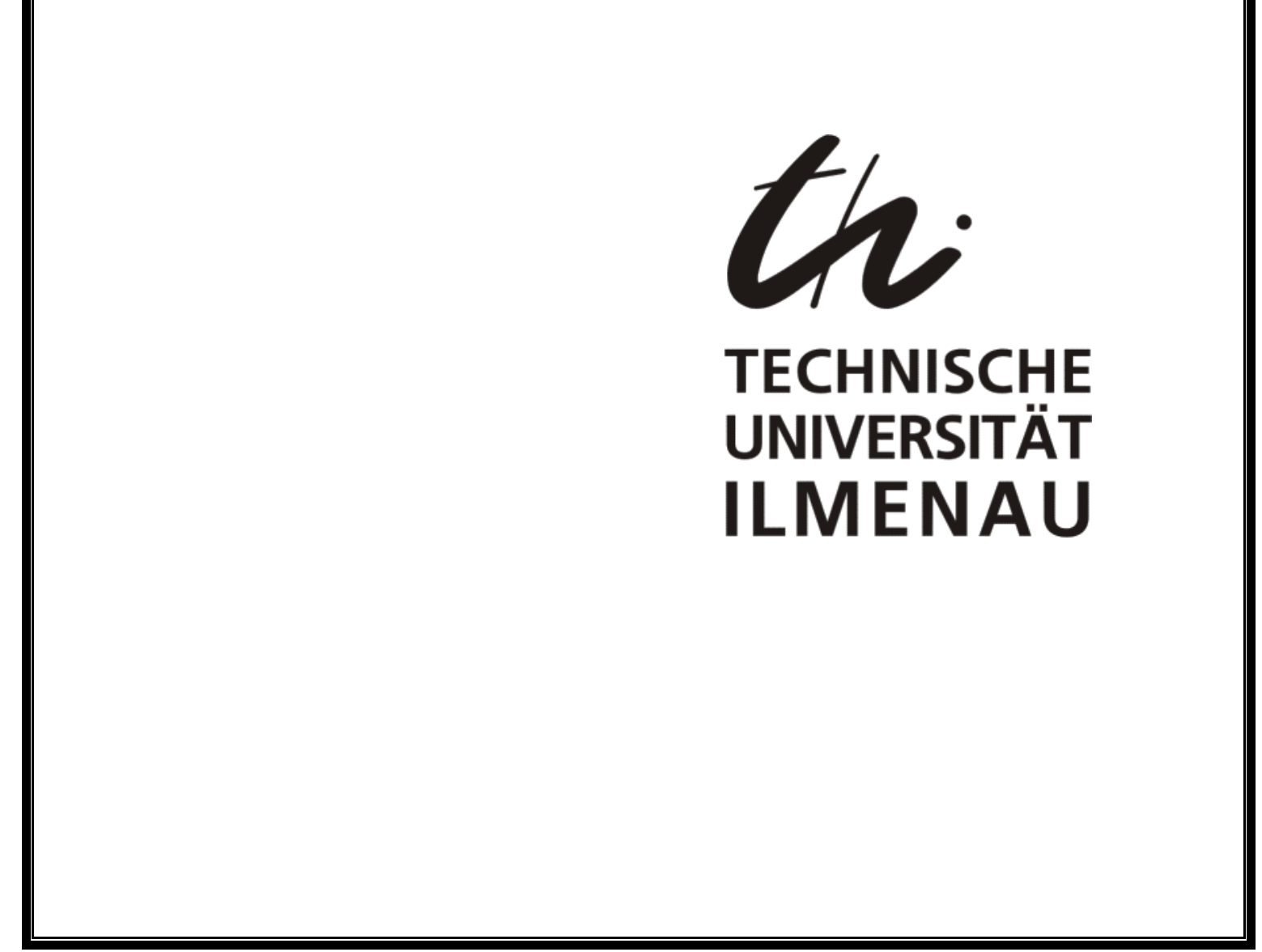

Medienpolitik - Regulierung der medialen öffentlichen Kommunikation

Gerhard Vowe

Nr. 4

November 2001

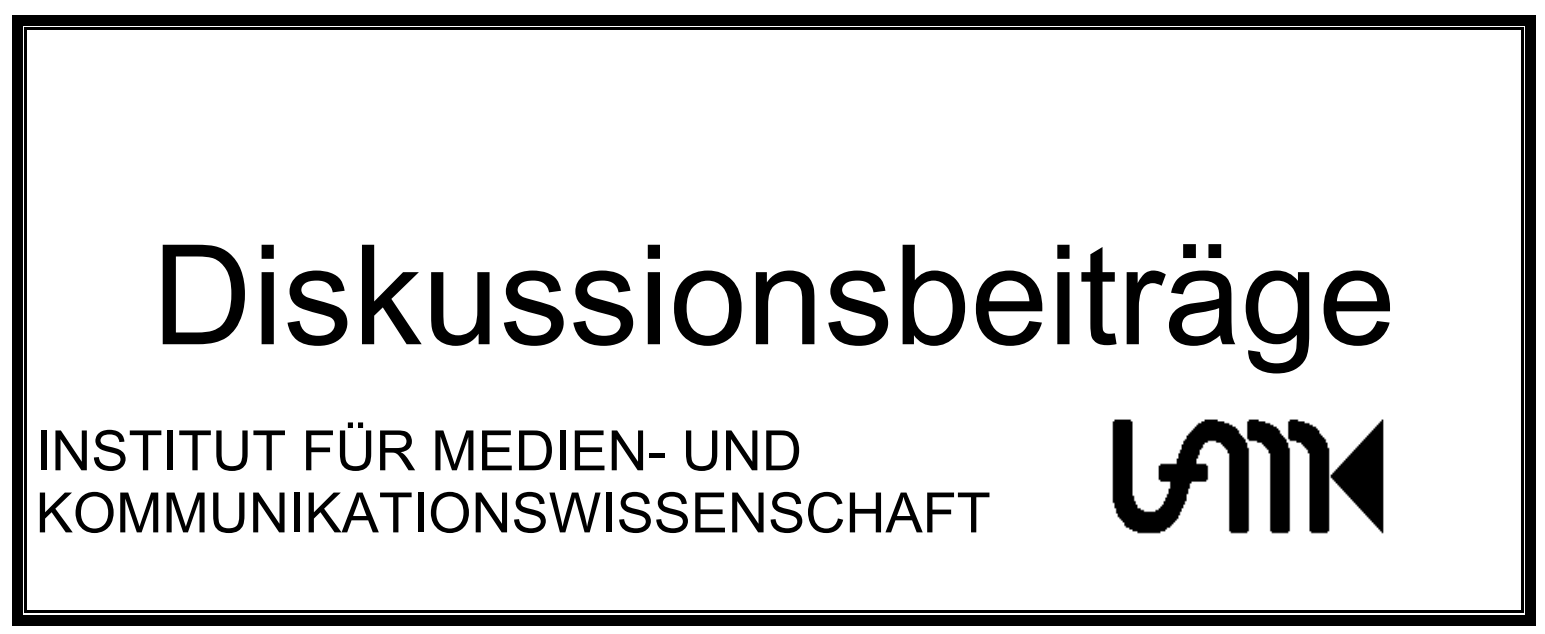




\title{
Medienpolitik - Regulierung der medialen öffentlichen Kommunikation
}

\author{
Gerhard Vowe
}

Nr. 4

November 2001

Herausgeber: Der Rektor der Technischen Universität IImenau

Redaktion: Institut für Medien- und Kommunikationswissenschaft

ISSN 1617-9048 


\section{Inhaltsübersicht}

\section{Medienpolitik - Regulierung der medialen öffentlichen Kommunikation}

Zusammenfassung

1. Medienpolitik exemplarisch - Eine Entscheidung des Bundesverfassungsgerichts ........ 7

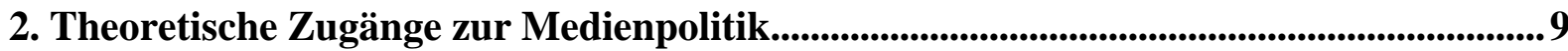

2.1 Historisches Denkmuster: Rekonstruktion von Entwicklung.......................................... 9

2.2 Juristisches Denkmuster: Auslegung grundlegender Normen ........................................ 10

2.3 Sozialwissenschaftliches Denkmuster: Erklärung aus Systemfunktionen .......................... 11

2.4 Ökonomisches Denkmuster: Begründung staatlicher Eingriffe ........................................ 12

\section{Medienpolitik aus entscheidungstheoretischer Perspektive - Allgemeine}

Dimensionen und spezielle Bereiche der Medienpolitik...............................................14

3.1 Medienpolitik als Entscheidung: Allgemeines Modell....................................................... 14

3.1.1 Wer entscheidet? Medienpolitik als Interaktion rationaler Akteure ....................................................... 16

3.1.2 Was wird entschieden? Medienpolitik als verbindliche Entscheidungen über Regeln für

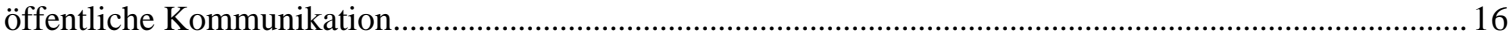

3.1.3 Wie wird entschieden? Medienpolitik als geregeltes Entscheidungsverfahren ...................................... 19

3.2 Differenzierung der Medienpolitik: Teilbereiche ........................................................... 20

4. Differenzierung von Interaktionsfeldern: Publizistik, Wirtschaft, Arbeit .......................22

4.1 Regulierung der publizistischen Beziehungen: Regeln für die Konkurrenz um

Einfluss auf die politische Meinungsbildung ...................................................................... 22

4.1.1 Grundlage der publizistischen Beziehungen: Wettbewerb um Aufmerksamkeit ................................22

4.1.2 Regulierung der Beziehung zwischen Politischen Organisationen und Medienorganisationen ............24

4.1.3 Regulierung der Beziehung zwischen politischen Organisationen........................................................26

4.2 Regulierung der wirtschaftlichen Beziehungen: Regeln für die Medienmärkte ................. 26

4.3 Regulierung der Arbeitsverhältnisse: Regeln für die Beziehungen in den

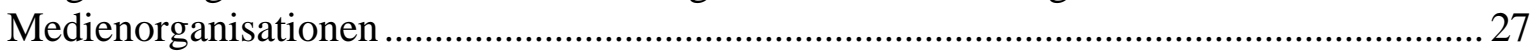

5. Differenzierung von Medienbereichen: Presse, Rundfunk, Online ......................................29

5.1 Pressepolitik in Deutschland: Konstanz und Konsens an der medienpolitischen

Peripherie

5.1.1 Regulierung der Presse als einem publizistischen Faktor ...............................................................29

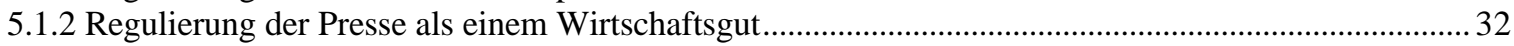

5.1.3 Fazit: Pressepolitik - vom Zentrum an den Rand der Medienpolitik.................................................33

5.2 Rundfunkpolitik in Deutschland: Detaillierte Regulierung - intensive Konflikte.............. 34

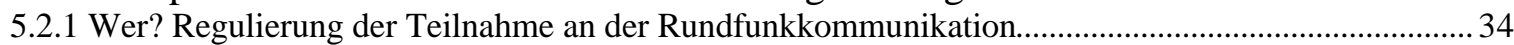

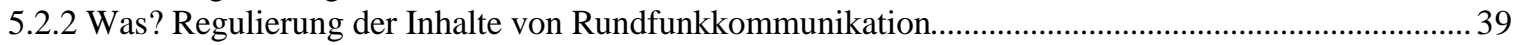

5.2.3 Wie? Regulierung der Prozeduren der Rundfunkkommunikation...................................................... 43

5.2.4 Fazit: Ökonomisierung und Europäisierung der Rundfunkpolitik...................................................... 44

5.3 Onlinepolitik in Deutschland: Regulierung im Schnittpunkt unterschiedlicher

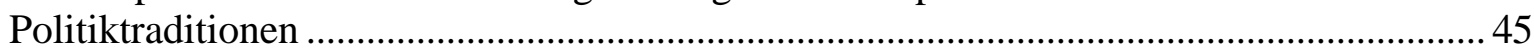

5.3.1 Regulierung durch wen? Massen- oder Individualkommunikation? ..................................................46

5.3.2 Wer? Regulierung der Teilnahme an der Onlinekommunikation..................................................... 47

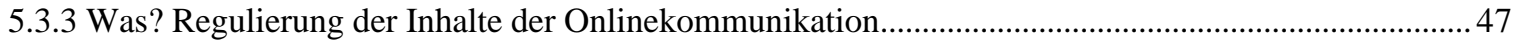

5.3.4 Wie? Regulierung der Prozeduren der Onlinekommunikation.......................................................... 49

5.3.5 Fazit: Rasante Entwicklung - stabilisiert durch Regulierung außerhalb des Rundfunks......................51 
6. Differenzierung von Entscheidungsebenen: Regulierung, Ordnung,

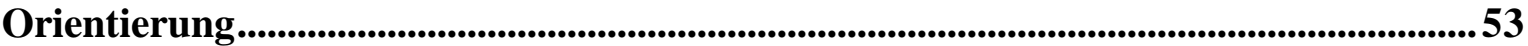

6.1 Der politisch-rechtliche Ordnungsrahmen: Restriktion der medienpolitischen

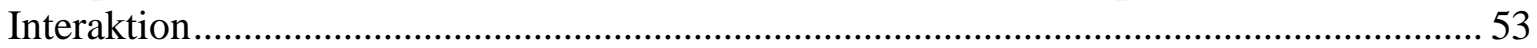

6.1.1 Kommunikationsfreiheiten: Grenzziehung zwischen Medien und Staat ........................................ 53

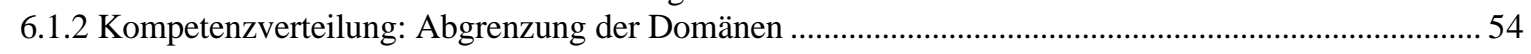

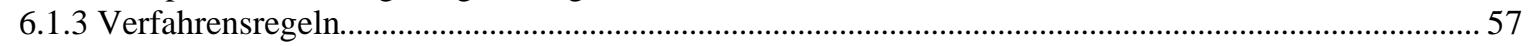

6.1.4 Fazit: Stabilität durch sachliche, soziale und zeitliche Strukturierung ................................................57

6.2 Politisch-kulturelle Orientierungsmuster: der Horizont der Medienpolitik ......................... 57

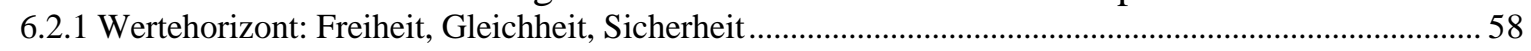

6.2.2 Kommunikationsbild: Starke Medien und schwache Massen .......................................................... 58

7. Fazit: Medienpolitik im Spannungsfeld von Medien, Politik und Wissenschaft ...........60

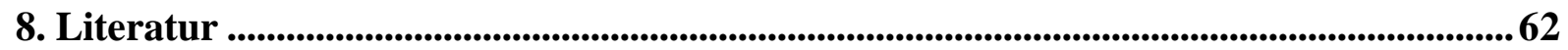




\section{„,Viele haben sich Republiken und Fürstentümer ausgemalt, von deren Existenz man nie etwas gesehen, noch vernommen hat. Mir scheint es richtiger, mich an die tatsächliche Gestalt der Dinge zu halten als an ein Phantasiebild. “}

Niccolo Machiavelli, 1532 (Der Fürst, 15.Kap.)

\section{Zusammenfassung}

1. Auf dem Hintergrund der unterschiedlichen kommunikationswissenschaftlichen Ansätze zu einer Theorie der Medienpolitik wird im Anschluss an den Public-Choice-Ansatz ein entscheidungstheoretisch basiertes generelles Modell von Medienpolitik entwickelt. Dabei werden bindende Entscheidungen in den Mittelpunkt gerückt und vier Aspekte unterschieden: Entscheidungsinhalte, Entscheidungsakteure, Entscheidungsprozesse und Entscheidungsrahmen.

Den substantiellen Kern von Medienpolitik bilden Regulierungen - verbindliche Entscheidungen über die Rahmenbedingungen, unter denen öffentlich kommuniziert wird, z. B., ob es Fernsehdirektübertragungen aus Gerichtssälen geben darf oder nicht. Diese Bedingungen fungieren als Begrenzungen für den Handlungsraum derjenigen, die in verschiedenen Rollen (Sprecher, Vermittler, Hörer etc.) und in verschiedenen Kontexten (Politik, Wirtschaft, Sport etc.) öffentlich kommunizieren.

Regulierungen sind das Ergebnis von Interaktionen. Sie werden in institutionalisierten Akteurskonstellationen ausgehandelt, zu denen sich vor allem staatliche Instanzen, Parteien und Medienorganisationen bzw. deren Verbände gruppieren, die in erster Linie ihre jeweiligen Interessen verfolgen. Je größer bei der Setzung und Durchsetzung von Regeln das Gewicht staatlicher Instanzen ist, desto mehr kann man von hoheitlicher Steuerung sprechen, je größer das Gewicht der Verbände ausfällt, desto mehr von Selbstregulation. Die Akteure divergieren über den Grad an Einschränkungen, die ihrem Handeln auferlegt werden, sie konvergieren im Interesse an Regeln, die allen Akteuren gleiche und stabile Rahmenbedingungen garantieren.

Medienpolitische Entscheidungen bilden eine komplexe prozessuale Struktur aus Teilentscheidungen, Vorentscheidungen, Folgeentscheidungen. Sie werden unter hoher Unsicherheit getroffen und zeitigen Folgen, die in nur begrenzt vorhersehbarer Weise auf die Ausgangsbedingungen zurïckwirken. Reduziert wird die hohe Komplexität des Entscheidungsprozesses durch Verfahrensregeln.

Für das stabilisierende Gegengewicht sorgt ein Rahmen aus Regeln für die Entscheidung, innerhalb dessen die Entscheidungen getroffen werden. Durch ihn wird das Spektrum möglicher 
Entscheidungsalternativen begrenzt, die Interaktion strukturiert und der Prozess prozedural eingerüstet.

2. Auf Basis dieses allgemeinen Modells werden spezielle Bereiche der Medienpolitik differenziert. Diese Differenzierung kann in unterschiedlichen Dimensionen erfolgen: im Hinblick auf Interaktionsfelder, auf Medienbereiche und auf Entscheidungsebenen. Auf diese Weise werden in dreifacher Weise Teilbereiche der Medienpolitik unterschieden, die gesondert untersucht werden können. Eine Differenzierung im Hinblick auf Entwicklungsabschnitte (Epochen) ist ebenfalls analytisch relevant, kann hier aber nicht geleistet werden.

3. Eine funktionale Differenzierung wird im Hinblick auf Interaktionsfelder vorgenommen. Dabei werden die medialen Beziehungen unterschieden, die durch Regulierungen strukturiert werden.

Von zentraler Bedeutung sind die Beziehungen zwischen politischen Organisationen und Medienorganisationen. Die Regulierungen begrenzen - also öffnen und schließen - den Handlungsraum der politischen Organisationen, wie z. B. den der Parteien, die via Medien um Zustimmung beim politisch relevanten Publikum konkurrieren und auf diese Weise Einfluss auf die Bildung öffentlicher Meinung zu nehmen versuchen. Publizistische Regulierungen können aus den Interessen der nutzenmaximierenden politischen Akteure erklärt werden. Begründungen für Regulierungen, die auf der Makroebene ansetzen (Integration, Gemeinwohl u.a.), erweisen sich in diesem Licht als Rechtfertigungen der politischen Akteure, nicht als tragfähige Erklärungen für die Regulierungen.

Zum anderen wird mit Regulierung der Handlungsraum von Medienorganisationen, wie z. B. Rundfunkanbietern, begrenzt, die um die Aufmerksamkeit von Zielgruppen konkurrieren. Auch die Beziehungen auf anderen medienrelevanten Märkten werden durch Regeln strukturiert, so auf dem Insertions-, dem Rechte- und dem Standortmarkt.

Ein drittes relevantes Interaktionsfeld sind die Arbeitsbeziehungen innerhalb der Medienorganisationen.

4. Eine segmentäre Differenzierung wird im Hinblick auf Medienbereiche vorgenommen. Die Akteurskonstellationen, die Schwerpunkte der Regulierung und die Verfahren differieren so stark von Medienbereich zu Medienbereich, dass man von Pressepolitik, Rundfunkpolitik und Onlinepolitik als voneinander unterscheidbaren Teilbereichen der Medienpolitik sprechen kann. Regulierungen in diesen Bereichen lassen sich vor allem danach unterscheiden, an welchem von drei Elementen der öffentlichen Kommunikation sie ansetzen:

- Regulierung der Teilnahme: Wer soll und wer soll nicht in bestimmten Rollen an der öffentlichen Kommunikation teilnehmen? 
- Regulierung der Inhalte: Was soll und was soll nicht öffentlich kommuniziert werden?

- Regulierung der Prozeduren: Wie soll und wie soll nicht öffentlich kommuniziert werden?

In der Pressepolitik wird die Teilnahme an der Produktion und Distribution nur schwach reguliert. Enger ist das Netz an inhaltlichen Regeln, z. T. hoheitlich gesetzt, z. T. in Selbstregulation gebildet. Die Regelungen für die Beziehungen der Presseanbieter untereinander (z. B. Wettbewerbsregelungen) und die Beziehungen innerhalb der Presseorganisationen (z. B. Mitbestimmungsregelungen) sind aus politisch-publizistischen Gründen rigider gefasst als in anderen Branchen. Insgesamt ist die Akteurskonstellation der Pressepolitik durch starke Verbände und schwache staatliche Instanzen gekennzeichnet. Pressepolitik basiert auf einem breiten Konsens und hat eine hohe Konstanz entwickelt.

In der Rundfunkpolitik - Domäne der Bundesländer bei wachsendem Einfluss der EU - wird über das Instrument der Zulassung kontrolliert, wer als Rundfunkanbieter fungieren kann. In die Struktur der Programme wird mit hoheitlichen Setzungen eingegriffen: bei öffentlichrechtlichen und bei privaten Anbietern; in den redaktionellen und in den insertionellen Teil. In die Prozeduren des Rundfunks wird ebenfalls regulativ eingegriffen, z. B. dadurch, dass die Folgen exklusiver Übertragungsrechte abgefedert werden.

In der Onlinepolitik wird auf eine Regulierung der Nutzerzusammensetzung verzichtet - weder durch ein Zulassungsverfahren noch durch einen Universaldienst. Die Verantwortung für rechtlich relevante Inhalte ist gestaffelt worden. Bei den Prozeduren sind auf nationaler Ebene vor allem Regelungen für den Datenschutz und für die Authentifizierung, auf transnationaler Ebene vor allem für die Adressierbarkeit der Teilnehmer getroffen worden. Die nationalen Regelungen sind in einem „Kompetenz-Sharing“ zwischen Bund und Ländern getroffen worden, die transnationalen Regelungen durch Selbstregulation der Teilnehmer an der Online-Kommunikation bei wachsendem Einfluss von Unternehmen.

5. Eine strukturelle Differenzierung wird im Hinblick auf Entscheidungsebenen vorgenommen.

So wie die Regulierungen Restriktionen für das kommunikative Handeln darstellen, so sind die Regulierungen ihrerseits Restriktionen unterschiedlicher Art unterworfen. Über die Regulierungsentscheidungen wird wiederum entschieden, z. B. in Form von Kompetenzentscheidungen (wer darf entscheiden und wer nicht?).

Die Entscheidungen für oder gegen bestimmte Möglichkeiten der Regulierung werden zugleich ermöglicht und eingeschränkt durch einen übergreifenden, vor allem verfassungsrechtlich kodifizierten rechtlich-politischen Ordnungsrahmen. Dessen tragende Bestandteile sind die Kommunikationsfreiheiten, die Kompetenzverteilung und Verfahrensregeln - alles Entscheidungen über (Regulierungs-)Entscheidungen. Die einzelnen Elemente dieses Ordnungsrahmens gehen auf politische Entscheidungen zurück und sind dementsprechend von politischen Auseinander- 
setzungen geprägt. Er ist aber dem politischen Tagesgeschäft entzogen und unterliegt nicht der unmittelbaren Disposition der Akteure. Der Ordnungsrahmen prägt die Regulierungen, determiniert sie aber nicht - es verbleibt Spielraum. Jede Regulierung bestätigt wiederum den Ordnungsrahmen, indem sie die grundlegenden Vorgaben aktualisiert.

Der Ordnungsrahmen ist seinerseits geprägt von der grundlegenden politisch-kulturellen Orientierung, insbesondere vom Wertehorizont, der in einer Gesellschaft für die Auswahl von Regulierungsentscheidungen und Ordnungsentscheidungen maßgebend ist. Orientierend wirkt außerdem das dominante Bild von Medien, insbesondere die Unterstellung starker, direkter, genereller Wirkungen von Medien.

6. Letztlich ist somit die Medienpolitik in den grundlegenden Schemata, u. a. in den Medienwirkungsannahmen verankert. Damit besteht eine Möglichkeit für die Wissenschaft, nicht nur durch empirische Forschung zu Ursachen und Wirkungen von Regulierung zu einer Rationalisierung politischer Entscheidungen beizutragen, sondern auch durch die Prüfung der Medienwirkungshypothese ein Gegengewicht zu Alarmierung und Verharmlosung zu bilden. Das setzt voraus, dass sich die Forschung aus dem Paradigma der Makrofunktionen löst, ohne sich auf der Mikroebene einzelner Entscheidungen zu verlieren. 


\section{Medienpolitik exemplarisch - Eine Entscheidung des Bundesverfassungsgerichts}

Am 24.1.2001 wies das Bundesverfassungsgericht (BVerfG) eine Verfassungsbeschwerde des Nachrichtensenders n-tv zurück. ${ }^{1}$ Der hatte in dem Verbot von Fernsehaufnahmen aus Gerichtssälen einen unverhältnismäßigen Eingriff in die Rundfunkfreiheit gesehen. Das BVerfG sah die restriktiven Vorschriften als geboten an, um die Persönlichkeitsrechte der Angeklagten und Zeugen zu schützen und um eine ungestörte Wahrheits- und Rechtsfindung im Verfahren zu gewährleisten. Eine unmittelbare Fernsehberichterstattung bringe die Gefahr mit sich, dass sich einerseits die Beteiligten auf eine Medienöffentlichkeit ausrichteten und anderseits der öffentliche Druck auf das Gericht verstärke. In einer abweichenden Meinung forderten drei der sieben Richter mit Blick auf die gestiegene Bedeutung der Medienöffentlichkeit eine Abkehr vom ausnahmslosen Verbot und eine Differenzierung zwischen unterschiedlichen Verfahrensarten und - abschnitten.

Mit dieser Entscheidung wurde eine Regelsetzung für kommunikative Beziehungen verfassungsrechtlich bekräftigt. Es bleibt weiterhin rechtlich untersagt, dass durch Direktübertragungen von spektakulären Prozessen

- $\quad$ ein Sender Vorteile in der Konkurrenz um die Publikumsgunst oder

- eine gerichtliche Partei Vorteile in der Konkurrenz um die Mobilisierung der öffentlichen Meinung

zu erreichen versucht.

Durch den Kontrast von Mehrheits- und Minderheitsvotum wurde deutlich, dass diese Entscheidung eine Auswahl aufgrund unterschiedlicher Präferenzbildungen bedeutet: Die Mehrheit kam in der Abwägung zwischen den Rechten von Verfahrensbeteiligten und den Anforderungen einer gewandelten Öffentlichkeit zu einem anderen Ergebnis als die Minderheit.

Diese Entscheidung ist bindend - mit der Regelsetzung wird das zukünftige kommunikative Handeln in verbindlicher Weise eingeschränkt, bis zu einem gewissen Grade auch das des BVerfG selbst.

Diese Entscheidung war Ergebnis einer Interaktion - innerhalb und außerhalb der Mauern des Gerichts, mit formellen und informellen Abschnitten. Dabei kooperierten 
und konfligierten die Akteure - das Gericht, die Stellung nehmenden Verbände und die Medienorganisationen selbst. Herr des Entscheidungsprozesses blieb stets das BVerfG es konnte die Interaktion zeitlich, sachlich und sozial strukturieren. Die Akteurskonstellation war folglich stark asymmetrisch.

Die Bindungskraft der Regel und die Formalisierung des Entscheidungsprozesses zeigen, dass die Entscheidung Ausdruck und zugleich Bestätigung eines Ordnungsrahmens war, nicht aber zwingende Folge daraus. Denn die grundlegenden Rechtsregeln, wie z. B. die Kompetenzzuweisung für das BVerfG oder Verfahrensvorschriften, determinierten nicht die getroffene Entscheidung.

Und letztlich beruhten die Entscheidung und der Ordnungsrahmen auf kollektiven Orientierungsmustern mit zentralen Unterscheidungen wie z. B. der zwischen Bildwirkung und Wortwirkung. Darauf basierte die grundlegende Annahme des Gerichts, dass dem Fernsehen eine besondere Kraft zukomme, die es in besonderem Maße zu zügeln gelte.

Im Beispiel dieser einzelnen Entscheidung tritt das kategoriale Gerüst hervor, mit dem im folgenden Medienpolitik beschrieben und erklärt wird. Dieses Analysemodell ist auf dem Hintergrund der verschiedenen Ansätze zu einer Theorie der Medienpolitik entwickelt worden.

\footnotetext{
${ }^{1}$ Vgl. BVerfG, 1 BvR 2623/95 v. 24.01.2001.
} 


\section{Theoretische Zugänge zur Medienpolitik}

Es gibt keine systematisch ausgearbeitete und im Fach und darüber hinaus akzeptierte Theorie der Medienpolitik; vielmehr gibt es eine Reihe von Ansätzen, die den Anspruch erheben, Medienpolitik beschreiben, erklären und voraussagen bzw. gestalten zu können. In Übereinstimmung mit dem Profil der Kommunikationswissenschaft als einer Integrationswissenschaft ist die Theorie der Medienpolitik davon geprägt, dass unterschiedliche Bezüge zu anderen Disziplinen darum konkurrieren, das dominante Muster in der Analyse von Medienpolitik zu bilden. Im folgenden werden die vier wichtigsten Fachbezüge charakterisiert, die jeweils eigene Modelle, Kategorien und Methoden ausgebildet haben: der historische, der juristische, der sozialwissenschaftliche und der ökonomische Zugang zur Medienpolitik. Diese Muster prägen parallel das Verständnis von Medienpolitik; eine zeitliche Abfolge in der Dominanz ist nicht erkennbar. ${ }^{2}$ Die Differenzierung von Ansätzen innerhalb dieser Denkmuster kann nur angedeutet werden. Im Anschluss daran wird ein synthetisierendes Modell der Medienpolitik entwickelt, das die Hauptelemente der konkurrierenden Denkmuster aufgreift.

\subsection{Historisches Denkmuster: Rekonstruktion von Entwicklung}

Ein historisches Denkmuster liegt zugrunde, wenn Medienpolitik erzählt, d. h. in einer chronologischen Abfolge dargestellt wird. Den kognitiven Ausgangspunkt dieses Zugangs zur Medienpolitik bildet die Rekonstruktion von Entwicklung. Das Schwergewicht liegt auf Ereignissen, insbesondere politischen Entscheidungen, die aus ihrem jeweiligen Kontext und vor allem aus den vorangegangenen Ereignissen heraus begründet werden. Besonders deutlich wird dies in den Chroniken der Medienpolitik für die Bundesrepublik Deutschland ${ }^{3}$ und an den medienpolitischen Teilen von Überblicksdarstellungen. ${ }^{4}$ Umgekehrt wird sowohl in den epochenübergreifenden ${ }^{5}$ als auch in epochenspezifischen medienhistorischen Abhandlungen ${ }^{6}$ der Medienpolitik prägende Kraft für die jeweilige Medienentwicklung zugeschrieben. Innerhalb dieses Musters finden sich erhebliche Differenzierungen, etwa in der Systematisierung der Epochen oder in der jeweiligen Gewichtung von Ereignis und Kontext. ${ }^{7}$ So weit diese Arbeiten über die Deskription von Verläufen hinausgelangen, werden Entwicklungsstrukturen und Typen

\footnotetext{
${ }^{2}$ Anders: Rühl 1985. Nicht zuzuordnen sind generelle Einführungen wie Tonnemacher 1996 oder Meyn 2001.

${ }^{3}$ Heinrich 1991; Kopper 1992; Schütz 1999.

${ }^{4}$ Stuiber 1998; Pürer/Raabe 1994.

${ }^{5}$ Z. B. Wilke 1999, 2000; Stöber 2000; Dussel 1999.

${ }^{6}$ Für Rundfunk: Lerg 1980, Bausch 1980.

${ }^{7}$ Z. B. Jürgens 1984 vs. Koszyk 1966, 1972.
} 
der Medienpolitik deutlich, die sich nach wie vor an den „Four Theories of the Press“ als einem Vorbild für historisch basierte Typologien orientieren (Schramm/Siebert/Peterson 1956). Besondere Aufmerksamkeit ist dem totalitären Typ der Medienpolitik gewidmet worden. ${ }^{8}$ Die zahlreichen historischen Fallstudien bieten detaillierte Einblicke in die Komplexität spezifischer medienpolitischer Konstellationen.

\subsection{Juristisches Denkmuster: Auslegung grundlegender Normen}

Der fachlich und politisch einflussreichste Zugang zur Medienpolitik ist rechtswissenschaftlicher Art. In diesem Muster wird Medienpolitik aus der Auslegung grundlegender Normen heraus begriffen - verbunden mit einem auch faktisch eingelösten Gestaltungsanspruch. Den kognitiven Ausgangspunkt bilden verfassungsrechtlich kodifizierte Leitwerte, in erster Linie die Kommunikationsfreiheiten, die in der medienrechtlich dominanten Interpretation als Freiheit der individuellen und kollektiven Meinungsbildung verstanden werden - eine entscheidende Voraussetzung für die Integration der Gesellschaft. Medien werden publizistisch, als „Medium und Faktor der Meinungsbildung“ gesehen, als Mittel der ,gesellschaftlichen Selbstbeschreibung“. Ihre Gemeinwohlorientierung stehe in steter Gefahr und sei insbesondere beim Rundfunk durch eine positiv definierte Ordnung zu sichern, mit der die publizistische Leistung gewährleistet werden kann: Freiheit durch Ordnung (,objektivrechtliches Element“ der Kommunikationsfreiheit). Andere Faktoren der Medienentwicklung wie ökonomische Erfordernisse, technische Möglichkeiten, soziale Veränderungen oder politische Interessen werden in diesem Denkmuster durchaus berücksichtigt, immer aber im Hinblick auf die freiheitssichernde Aufgabe der Medien eingeschätzt. Insbesondere für den Rundfunk war und ist dieses Denkmuster von unmittelbarer medienpolitischer Bedeutung. Denn es wurde im Zuge der Rechtsprechung des BVerfG entwickelt und fungiert nach wie vor als kognitive Folie zur Gestaltung des Rundfunkbereichs. ${ }^{9}$ Andere Interpretationsstränge der Verfassungsnormen konnten sich demgegenüber in Wissenschaft und Rechtsprechung nicht durchsetzen, etwa das traditional-liberale Verständnis von Kommunikationsfreiheit als einer individuellen Freiheit von Kommunikatoren und Rezipienten, die es gegen staatliche Eingriffe zu schützen gilt und aus deren ungehinderter Wahrnehmung sich erst die kollektiven Funktionen ergeben. ${ }^{10}$

\footnotetext{
${ }^{8}$ Z. B. Diller 1980; Frei/Schmitz 1989.

${ }^{9}$ Grundlegend: Hoffmann-Riem 1989, 1996: 114-158, 2000; Grimm 1995, 1999.

10 „Subjektivrechtliches Element“ der Kommunikationsfreiheit: vgl. Engel 1993: 27; Bullinger 1980: 118; Ricker/Schiwy 1997.
} 
Bei aller Pluralität der Staatsrechtslehre bzw. des Medienrechts formieren sich die verschiedenen Ansätze dennoch zu einem gemeinsamen Muster für die medienpolitische Analyse. Gemeinsam sind

- der Ausgangspunkt: grundlegende Normen

- die Methode: Interpretation von Normen und Kreation von Regeln

- der Anspruch: Begründung und Gestaltung statt Erklärung.

\subsection{Sozialwissenschaftliches Denkmuster: Erklärung aus Systemfunktionen}

Für sozialwissenschaftlich orientierte Autoren ist die Erklärung aus Systemfunktionen ein charakteristischer Zugang zur Medienpolitik - mit Verbindungen zum juristischen Muster über die grundlegenden Normen und zum historischen über die Entwicklungsstrukturen. Sie argumentieren bevorzugt in einem strukturell-funktionalen Paradigma: Medienpolitische Strukturen werden aus ihrer Leistung für die gesellschaftliche Makroebene erklärt. Daraus wird gefolgert, dass die Medien gesteuert werden müssen, damit sie basale Systemprobleme lösen, wie z. B. gesellschaftliche Integration oder Kontrolle politischer Macht. Erst Medienpolitik bringe die generellen funktionalen Anforderungen an Medien zum Ausdruck? ${ }^{11}$ Die Kommunikationswissenschaft reagiert auf die „Steuerungsprobleme des Mediensystems“ (Saxer 1994: 23), entwickelt Lösungen als Vorgaben für die Medienpolitik und bewertet die Medienpolitik entsprechend. Insofern sind auch die politologisch und soziologisch orientierten Arbeiten von normativen Vorgaben im Hinblick auf die Funktionen von Medien geprägt. Dabei sind die Bestimmungen sehr unterschiedlich, was Medien gesellschaftlich bewirken sollen und Medienpolitik folglich hemmen oder fördern soll. So steht bei Glotz (1966) die demokratische Teilhabe im Vordergrund; bei Langenbucher (1999) die gesellschaftliche Integration; bei Kepplinger (1982) die Bewahrung von Freiheitsräumen; bei Holzer (1973) Herrschaftssicherung und Legitimationsbeschaffung. Medienpolitik wird dabei nicht mehr allein dem Staat als Wirkungsbereich zugerechnet, sondern aus dem Zusammenwirken vieler Subsysteme begriffen, die das „Politisch-Administrative System“ ${ }^{\text {bilden. }}{ }^{12}$

Auf dieser kognitiven Basis sind zahlreiche empirische Arbeiten entstanden, bei denen einzelne Gestaltungsprozesse zumeist auf der Basis von Dokumentenanalysen und Ex-

\footnotetext{
${ }^{11}$ Wegweisend dazu: Ronneberger 1978, 1980, 1986; des weiteren Rühl 1973; Schatz /Lange 1982; Kepplinger 1982.

${ }^{12}$ So Schatz/Habig/Immer 1990; zusammenfassend Ronneberger 1995: 198.
} 
pertengesprächen rekonstruiert wurden. ${ }^{13}$ Dadurch wird ausschnittsweise die Komplexität der Interessenkonstellationen und Entscheidungsprozesse deutlich.

Parallel dazu hat sich ein komparatives Vorgehen als methodisch fruchtbar herausgestellt, bei dem medienpolitische Systeme im Hinblick auf ihre Strukturen und ihre Leistungsfähigkeit verglichen werden. ${ }^{14}$

Die autopoietische Wende in der soziologischen Systemtheorie hat sich insofern in der Theorie der Medienpolitik niedergeschlagen, als bei den entsprechend inspirierten $\mathrm{Au}-$ toren die Möglichkeiten der funktional begründeten Steuerung durch Medienpolitik skeptisch eingeschätzt werden. ${ }^{15}$

Z. T. in Abgrenzung, z. T. in Ergänzung zu systemtheoretischen Ansätzen hat sich eine akteurstheoretisch orientierte Linie herausgebildet, die Medienpolitik als Ergebnis der Interaktion politischer Interessen begreift und bevorzugt die Entwicklung von „PolicyNetzwerken“ und „Arenen“ in der Rundfunkpolitik nachzeichnet. Dabei wird an dem Konzept der Steuerung im Hinblick auf politische Ziele festgehalten, aber aus der Koppelung an eine hierarchische Struktur gelöst; stattdessen werden Alternativen wie „Kontextsteuerung“ und „,prozedurale Steuerung“ präferiert (z. B. Jarren/Donges 2000).

\section{4 Ökonomisches Denkmuster: Begründung staatlicher Eingriffe}

Aus der wirtschaftswissenschaftlichen Beschäftigung mit Medien hat sich ein weiteres Muster für die Analyse der Medienpolitik entwickelt - insbesondere über den Begriff der Regulierung. Zentral ist dabei die Rolle des Staates für die Medienwirtschaft: es geht um die normative Bestimmung von Notwendigkeit und Möglichkeit staatlicher Eingriffe in die Medienmärkte. ${ }^{16}$ Ausgangspunkt ist, dass der Wettbewerb zwischen den Marktteilnehmern gesamtgesellschaftlich und gerade auch publizistisch positive Wirkungen zeitige und jeglicher Eingriff in die empfindlichen Märkte als riskant und deshalb als begründungspflichtig angesehen wird. Die unterschiedlichen Formen und Intensitäten der Interventionen werden in der Normativen Wirtschaftswissenschaft unter Effizienzgesichtspunkten bewertet, ihre Begründungen geprüft (negative und positive externe Effekte, Meritorik, Paternalismus) und Empfehlungen insbesondere für die Rundfunkpolitik gegeben. Dabei wird weitgehend unterstellt, dass eine Regierung bestrebt sei, die Wohlfahrt eines Landes zu maximieren, und dies über eine medienöko-

\footnotetext{
${ }^{13}$ Z. B. Mettler-Meibom 1986; Wiek 1996; Eisermann 2001.

${ }^{14}$ Kleinsteuber 1993; Gellner 1990.

${ }^{15}$ Marcinkowski 1993; Grothe 2000.

${ }^{16}$ Heinrich 1999: 83ff; Kops 1999; Kruse 1996; Kiefer 2001; als Gegenpol mit dem Fokus auf Konzentrationskontrolle: Knoche 1978.
} 
nomische Politikberatung im Hinblick auf die Konsequenzen von medienpolitischen Entscheidungen auch unterstützt werden könne. 


\section{Medienpolitik aus entscheidungstheoretischer Perspektive - Allgemeine Dimensionen und spezielle Bereiche der Medienpolitik}

Die Pluralität dieser verschiedenen Denkmuster macht eine Synthese zugleich möglich und notwendig. In jedem der Denkmuster wird ein Aspekt von Medienpolitik betont, der für dichte Beschreibungen, plausible Erklärungen und handlungsrelevante Voraussagen von Bedeutung ist. Folglich nimmt das im folgenden entwickelte Modell von Medienpolitik alle diese Aspekte auf, verzichtet jedoch in Abgrenzung zu den dargestellten Ansätzen möglichst weitgehend auf normative Vorgaben. Die Orientierung auf normative Vorgaben - ob verfassungsrechtliche Leitwerte, ökonomische Ziele oder soziale Funktionen - hat die Erklärungskraft der Forschung nicht gestärkt. Denn die tatsächlich getroffenen medienpolitischen Entscheidungen, ihre Voraussetzungen und Konsequenzen sind nicht aus den normativen Vorgaben zu deduzieren. Darüber hinaus sind die normativen Vorgaben selbst erklärungsbedürftig.

Die Einbindung der verschiedenen disziplinären Aspekte in einen einheitlichen Erklärungszusammenhang ermöglicht der Public-Choice-Ansatz, ${ }^{17}$ mit dem ökonomische Modelle ihre Beschränkung auf wirtschaftsbezogene Entscheidungen verlieren und an Relevanz für politische Entscheidungen generell gewinnen; sie können sich bei der Analyse öffentlicher Entscheidungsprozesse zu Problemen von allgemeiner Relevanz mit kollektiv bindenden Ergebnissen angewendet werden.

Die Anwendung dieses Ansatzes auf Medienpolitik beruht auf entscheidungs-, institutions- und kommunikationstheoretischen Grundlagen, die im folgenden dargestellt werden. Dabei wird zunächst ein allgemeines Modell von und für Medienpolitik entwickelt (3.1); auf dieser Basis können dann in verschiedener Hinsicht Differenzierungen vorgenommen und auf diese Weise spezielle Teilbereiche der Medienpolitik unterschieden werden (3.2).

\subsection{Medienpolitik als Entscheidung: Allgemeines Modell}

„Medienpolitik“ ist abzugrenzen von „Politischer Kommunikation“. Sinnvollerweise kann nicht immer schon dann von Medienpolitik gesprochen werden, wenn es um Wirkungen von Medien auf Politik geht, und auch nicht schon dann, wenn sich Politik der

\footnotetext{
${ }^{17}$ Im deutschen Sprachraum haben sich die Begriffe „Neue Politische Ökonomie“ oder „Ökonomische Theorie der Politik“ eingebürgert (vgl. Frey/Kirchgässner 1994: 6). Die grundlegenden Arbeiten finden sich in der Sammlung Rowley 1993a-c. Für die Anwendung im Medienbereich siehe z. B. Bizer 1999, Große Holtforth 2000.
} 
Medien bedient, z. B. in Form von Öffentlichkeitsarbeit. ${ }^{18}$ Vielmehr kann erst dann von Medienpolitik die Rede sein, wenn es um Entscheidungen über mediale Kommunikation geht. Sie bilden den Kern von Medienpolitik und rücken in den Fokus des analytischen Modells. Folglich bietet sich an, die medienpolitische Analyse auf ein entscheidungstheoretisches Fundament mit drei tragenden Komponenten zu stellen, die dadurch gewonnen werden, dass die zentralen Dimensionen von Entscheidung unterschieden werden. In diesen Dimensionen werden im folgenden Festlegungen getroffen, die das Profil des Ansatzes ausmachen - zum Typ des Akteurs, zur spezifischen Substanz und zum Wirkungsbereich der Entscheidungen, zur Art des Entscheidungsverfahrens. Alles dies sind Vorentscheidungen, von denen die weitere Argumentation geprägt wird.

\section{Abbildung 1}

Allgemeines Modell: Dimensionen medienpolitischer Entscheidung

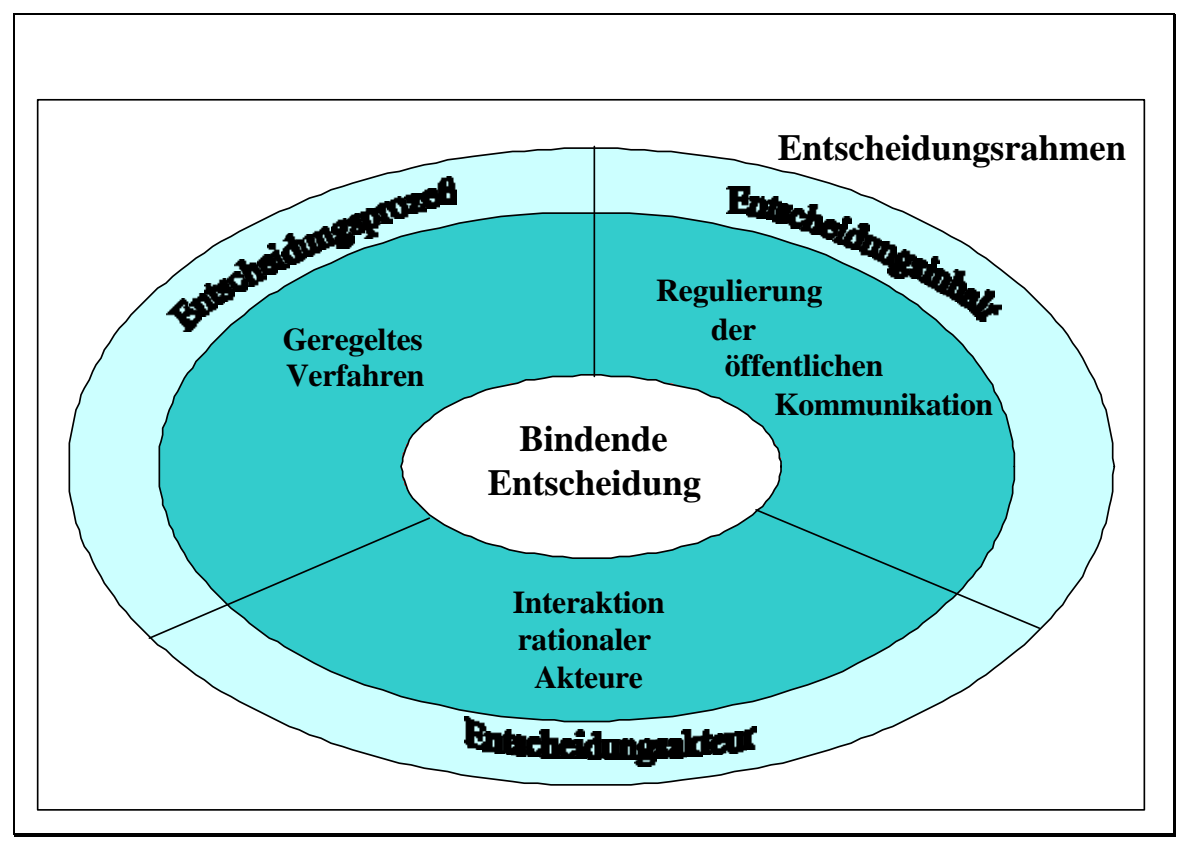

\footnotetext{
${ }^{18}$ Ebensowenig ist bereits die Nutzung des Telefons durch Politiker Telekommunikationspolitik, sondern erst verbindliche Entscheidungen im Hinblick auf das Telefon (z. B. zur Veröffentlichung von Abhörprotokollen). Eine Definition von Medienpolitik als „Maßnahmen ..., die direkt oder indirekt auf die Produktion, Distribution und den Konsum massenmedial verbreiteter Inhalte einwirken“ (Schatz/Habig/Immer 1990: 332) zieht nicht klar genug die Grenze zwischen medialem politischen Handeln und medienpolitischen Entscheidungen. Im betriebswirtschaftlichen Kontext wird „Kommunikationspolitik“ als Gesamtheit der organisierten externen Kommunikationsbeziehungen eines Unternehmens verstanden (vgl. Kepplinger 1994: 117). Saxer 1986: 149 unterscheidet zwischen einer ,theoretischen wissenschaftlichen Kommunikationspolitik“ und einer ,,angewandten wissenschaftlichen Kommunikationspolitik“, der die Optimierung der ,praktischen Kommunikationspolitik“ von Organisationen obliegt.
} 


\subsubsection{Wer entscheidet? Medienpolitik als Interaktion rationaler Akteure}

Betrachtet man Entscheidungen unter dem Aspekt ihrer Sozialstruktur, so tritt die Akteurskonstellation zu Tage, von der die Entscheidungen getragen werden. Im Hinblick darauf werden im Modell folgende Annahmen gemacht:

Entscheidungen werden von Akteuren ${ }^{19}$ getroffen und sind Ergebnis eines akteursinternen Zusammenwirkens von Wollen, Wissen und Können - also von Motivation, Kognition und Ressourcen. Grundannahme ist, dass die Akteure im Prinzip rational handeln, also diejenige Möglichkeit des Handelns auswählen, die das relativ günstigste Verhältnis von Kosten und Nutzen aufweist. ${ }^{20}$

Akteure handeln nicht isoliert, sondern in Akteurskonstellationen, in denen Interaktionen als Zusammenspiel von Konfrontation und Kooperation ablaufen.

Das Handeln unterliegt Restriktionen: der Spielraum der Akteure wird begrenzt durch Bedingungen, die sie selbst nicht kontrollieren können, wie die situativen Beschränkungen der Ressourcen, die konventionalisierten Weltbilder, die normative Prägung der Motive und die Spielregeln für die Auseinandersetzung mit anderen Akteuren.

Auf dieser Basis werden politische Entscheidungen nicht funktional als Lösungen gesellschaftlicher Probleme begriffen, sondern aktional aus dem Mit- und Gegeneinander eigennütziger Akteure innerhalb eines gegebenen Rahmens erklärt. Dies gilt auch für Entscheider im politischen Raum - sie orientieren sich ebenso wie alle anderen Akteure in erster Linie an ihrem eigenen Nutzen (vgl. Frey/Kirchgässner 1994).

\subsubsection{Was wird entschieden? Medienpolitik als verbindliche Entscheidungen über Regeln für öffentliche Kommunikation}

Betrachtet man Entscheidungen unter dem Aspekt ihrer Sachstruktur, so tritt der Gegenstand, die Substanz zu Tage, um den es bei der Entscheidung geht.

Das Spezifische von politischen Entscheidungen ist ihre kollektive Verbindlichkeit. Einen herausragenden Typ politischer Entscheidungen bilden Regulierungen - kollektiv verbindliche Entscheidungen über Regeln. ${ }^{21}$ In ihrer Sachstruktur sind politische

\footnotetext{
${ }^{19}$ Unter Akteur wird hier jede Einheit verstanden, der Entscheidungsfähigkeit unterstellt und damit Handlungen zugerechnet werden können - nicht nur im politischen Bereich. Zum Akteurskonzept des Rational Choice-Ansatzes siehe Elster 1999, Sen 1999, Esser 1999.

${ }^{20}$ Kosten und Nutzen gehen in unterschiedlichen Dimensionen in die Kalkulation ein (monetär, zeitlich, sozial, kognitiv). Einzubeziehen sind auch Kosten und Nutzen auf der Meta-Ebene, also z. B. für die entscheidungsbezogenen Informationsprozesse.

${ }^{21}$ Im Anschluß an Parsons 1969: 352 ff; vgl. Rühl 1973: 14, Münch 1976: 81 und Luhmann 1975. Im Unterschied zur wirtschaftswissenschaftlichen Begrifflichkeit (vgl. Weizsäcker 1982; Stigler 1975) wird unter Regulierung hier
} 
Entscheidungen somit eine Auswahl unter den konkurrierenden Alternativen, Regeln für ein bestimmtes Handeln zu setzen.

Die besonderen Merkmale der Regulierung sind der Entscheidungsgegenstand, also die Regeln, und die Bindungskraft, mit der die Setzung von Regeln ausgestattet ist. Beide Momente lassen sich institutionentheoretisch begründen ${ }^{22}$ : Soziale Regeln reduzieren die Komplexität von Handlungen und Erwartungen. Erst dadurch werden stabile soziale Beziehungen möglich. Für alle Formen von Interaktion bildet sich ein belastbares Gerüst mit differenten und indifferenten Bestandteilen. Regeln bieten eine „Gelegenheitsstruktur“, einen Rahmen für die Interessenverfolgung, der als Begrenzung des Spielraums fungiert, in dem sich die Akteure bewegen. Spielregeln haben Einfluss auf das Handeln; sie verändern die Wahrscheinlichkeiten von Handlungsmöglichkeiten, bestimmen aber nicht den Gang der Dinge - aus ihnen lässt sich nicht voraussagen, wie ein Spiel verlaufen wird. Einige Regeln werden gesetzt, d. h. über sie wird verbindlich entschieden, und ihre Befolgung wird durch eigens gebildete Organisationen gesichert, die mit Macht ausgestattet werden, um die Befolgung der Regeln notfalls auch gegen Widerstreben durchsetzen zu können - staatliche Instanzen. Regeln sind aber nur dann sinnvoll, wenn sie weitgehend selbstverständlich gelten und nicht von Fall zu Fall gegen Unwillen oder Unkenntnis durchgesetzt werden müssen. Das Handeln der für die Setzung und Durchsetzung von Regeln ausgebildeten Organisationen - vor allem, aber nicht ausschließlich das der staatlichen Instanzen - ist seinerseits in hohem Grade institutionalisiert, d. h. selbst wiederum gesetzten und sanktionsbewehrten Regeln unterworfen, so dass ihr Handeln mit hoher Erwartungssicherheit einhergeht. Ein Beispiel ist die Gesetzesbindung des bürokratischen Entscheidens. Regulierung und Restriktion stehen also in einem doppelten Bezug: Zum einen werden mit Regulierungen regulative Restriktionen des gesellschaftlichen Handelns gesetzt; zum anderen unterliegen die Regulierungen selbst wiederum Restriktionen, z. B. den Begrenzungen des Zeitraums für Entscheidungen.

Grundsätzlich haben alle Akteure Interesse an verbindlichen Regeln, da sich dadurch ihre Kosten für die Koordination untereinander reduzieren. So erhöht ein stabiler Rechtsrahmen die Wahrscheinlichkeit einer reibungslosen Vertragserfüllung und senkt dadurch die Transaktionskosten. Rechtssicherheit und sozialer Frieden, aber auch der allgemeine Bildungsstand, kulturelle Vielfalt und eine gut informierte Öffentlichkeit

nicht allein staatliche Regelsetzung verstanden. Eine Abgrenzung gegen Konzepte wie Steuerung kann hier nicht geleistet werden.

${ }_{22}$ Siehe dazu grundlegend Williamson 1990, North 1990, Scharpf 2000. 
sind öffentliche Güter, die bereitzustellen, einen erheblichen Aufwand erfordert, von deren Nutzung aber niemand ausgeschlossen werden kann und/oder bei deren Konsum keine Rivalität auftritt. Darum ist die Wahrscheinlichkeit hoch, dass Akteure es vorziehen, ein öffentliches Gut zu nutzen, ohne dafür entsprechende Aufwendungen zu leisten. Damit ist die kontinuierliche Bereitstellung des öffentlichen Gutes tendenziell gefährdet. Da aber alle ein - wenn auch niederrangiges - Interesse an der Bereitstellung der öffentlichen Güter haben, ist es politisch durchsetzbar, die Bereitstellung öffentlicher Güter durch verbindliche Regeln zu sichern, also z. B. über öffentliche Mittel zu finanzieren (Steuern) oder dafür sogar öffentliche Einrichtungen (Behörden) zu bilden. Dann verknüpfen sich mit der Bereitstellung öffentlicher Güter spezifische Interessen, zumeist bürokratische Nutzenkalküle. Es besteht aber weder empirisch noch theoretisch ein zwingender Zusammenhang zwischen öffentlichen Gütern, öffentlichen Mitteln und öffentlichen Einrichtungen (Frey/Kirchgässner 1994: 54).

Bei medienpolitischen Regulierungen geht es um Regeln als dem Kern der Rahmenbedingungen speziell für mediale öffentliche Kommunikation. Diese Regeln bilden einen Teil der Rahmenbedingungen, unter denen medial kommuniziert wird.

Einen anderen Teil bilden die Ressourcen für mediale Kommunikation, vor allem die finanziellen Budgets und die technischen Möglichkeiten, die auch von politischen Entscheidungen beeinflusst werden, z. B. von verbindlichen Entscheidungen über Subventionen und Besteuerung, über Infrastruktur und Forschungsförderung. Medienpolitische Entscheidungen beeinflussen somit alle Restriktionen für mediale Kommunikation, insbesondere aber die Regeln. Zudem ist verbindlich festzulegen, unter welchen Regeln Subventionen ausgereicht werden oder was mit den Ergebnissen öffentlich geförderter Forschung geschieht. Verteilungsentscheidungen müssen also auch auf Regeln abgestützt werden, um Bindungskraft zu erreichen. Medienpolitische Entscheidungen beschränken sich somit nicht auf Regelsetzung, aber die bildet den Kern von Medienpolitik und prägt die Medienpolitik insgesamt.

Medienpolitik bezieht sich auf einen Ausschnitt der Kommunikation und ist damit ein Teilbereich der Kommunikationspolitik. ${ }^{23}$ Man kann Humankommunikation auf zwei orthogonalen Dimensionen ordnen, nämlich Grad der Publizität (Eckpunkte: Intimkommunikation und Kommunikation, die prinzipiell von allen beobachtbar ist) und

\footnotetext{
${ }^{23}$ Die Abgrenzung von Medien- und Kommunikationspolitik wird von vielen Autoren anders gefasst: vgl. z. B. Ronneberger 1986; Schütz 1999; Kopper 1992; Jarren 1994; Kepplinger 1994; Kleinsteuber 1989.
} 
Grad der Medialität (Eckpunkte: Kopräsente Kommunikation und räumlich/zeitlich medial vermittelte Kommunikation). Entsprechend können unterschiedliche Bereiche von Kommunikationspolitik definiert werden. Medienpolitik sollte für den Quadranten der medial vermittelten öffentlichen Kommunikation reserviert werden. ${ }^{24}$

Mediale öffentliche Kommunikation wird hier aus der Optik der Ökonomik heraus als eine instrumentelle Beziehung aufgefasst, als eine spezielle Tauschbeziehung zwischen strategischen Akteuren. Die Akteure bilden als Anbieter und Nachfrager von bestimmten kommunikativen Gütern und Dienstleistungen spezifische Märkte, die durch die Regulierungen ihr spezifisches institutionelles Gerüst bekommen. Die Regulierungen wirken als Restriktionen; sie steuern weder das kommunikative Handeln der Akteure in dem Sinne, dass sie ihnen Ziel und Weg vorgeben - noch deren Präferenzen; aber sie beeinflussen beides dadurch, dass sie durch die Festlegung von Grenzen den Handlungsraum für manche Akteure erweitern, für andere verengen. ${ }^{25}$

\subsubsection{Wie wird entschieden? Medienpolitik als geregeltes Entscheidungsverfahren}

Betrachtet man Entscheidungen unter dem Aspekt ihrer Temporalstruktur, so tritt einmal ihre Dynamik zu Tage, zum anderen ihr Verhältnis zu vor- und nachgelagerten Entscheidungen. Es wird unter diesem Aspekt deutlich, wie die Entscheidungen sich miteinander verbinden, aneinander anknüpfen und voneinander abhängen. Entscheidungen bilden eine komplexe prozessuale Struktur aus Teilentscheidungen, Vorentscheidungen, Folgeentscheidungen. Sie werden unter hoher Unsicherheit getroffen und zeitigen Folgen, die in nur begrenzt vorhersehbarer Weise auf die Ausgangsbedingungen zurückwirken und Festlegungen für zukünftige Entscheidungen bedeuten. Reduziert wird die hohe Komplexität des Entscheidungsprozesses durch Verfahrensregeln; erst diese Überführung des Prozesses in eine Prozedur ermöglicht Entscheidungen. Der Ablauf wird dadurch gebändigt - im klassischen Wortsinne „reguliert“.

Für das stabilisierende Gegengewicht sorgt ein Rahmen aus Regeln für die Entscheidung, innerhalb dessen die Entscheidungen getroffen werden. Durch diese reflexive Struktur wird das Spektrum möglicher Entscheidungsalternativen begrenzt, die Interaktion strukturiert und der Prozeß prozedural eingerüstet und damit die Erwartbarkeit von Regulierungen erhöht (siehe dazu 6).

\footnotetext{
${ }^{24}$ Andere Bereiche aus dem Gesamt von Kommunikationspolitik sind Regelungen für die private medial vermittelte Kommunikation (z. B. „Individualkommunikation“ via Telefon oder E-Mail) oder Regelungen für die öffentliche nicht-mediale Kommunikation (z. B. Wochenmärkte, Parteiversammlungen usw.).

${ }^{25}$ Dies schließt an den Begriff der Kommunikationspolitik bei Rühl 1973: 12 an.
} 


\subsection{Differenzierung der Medienpolitik: Teilbereiche}

Ausgangspunkt ist also: Den Kern von Medienpolitik bilden kollektiv bindende Entscheidungen über Regeln für die mediale öffentliche Kommunikation. Diese Regulierungen sind Ergebnis einer Interaktion zwischen rationalen Akteuren, deren Handeln von ihren Motiven, Kognitionen und Ressourcen geprägt ist. Mit diesen Entscheidungen wird ein institutionelles Gerüst für die Tauschbeziehungen zwischen Kommunikationsakteuren geschaffen. ${ }^{26}$ Die medienpolitischen Regulierungen stehen ihrerseits in einem Rahmen und sind von Entscheidungen über Entscheidungen geprägt.

Auf Basis dieses generellen Modells kann medienpolitische Regulierung differenziert werden. Die analytische Bildung von Teilbereichen kann nach verschiedenen Gesichtspunkten erfolgen. In erster Linie kommen drei Dimensionen dafür in Frage ${ }^{27}$ :

- Interaktionsfelder: In einer funktionalen Dimension werden die verschiedenen Typen von kommunikativen Beziehungen differenziert, die durch Regelsetzung strukturiert werden (Kapitel 4). Im Mittelpunkt stehen dabei die publizistischen Beziehungen.

- Medienbereiche: In einer segmentären Dimension werden die Bereiche medialer Kommunikation differenziert, in denen sich unterschiedliche Regulierungsstrukturen entwickelt haben (Kapitel 5). Im Mittelpunkt steht dabei der Rundfunk.

- Entscheidungsebenen: In dieser strukturellen Dimension werden die Ebenen differenziert, auf denen Entscheidungen fallen. Im Mittelpunkt steht die Regulierung als Entscheidungstyp - sie ist aber in den anderen Kapiteln eingehend behandelt worden, so dass sich die Darstellung auf die anderen Entscheidungsebenen - den Ordnungsrahmen und die Orientierungsmuster - konzentrieren kann (Kapitel 6 und 7).

\footnotetext{
${ }^{26}$ Die Rollen müssen differenziert werden - Kommunikationsakteure treffen Entscheidungen im Hinblick auf Angebote und Nachfrage auf den Medienmärkten. Regulierungsakteure treffen Entscheidungen im Hinblick auf die Regelsetzung für die Beziehungen der Kommunikationsakteure. Diese Rollen können selbstverständlich von den gleichen Organisationen bzw. Individuen eingenommen werden.

${ }^{27}$ Eine weitere mögliche Differenzierung wäre die Unterscheidung von Phasen bzw. Epochen, also eine Darstellung der Medienpolitik im zeitlichen Ablauf. In diesem Falle würde die Verschiebung von Schwerpunkten beobachtbar, z. B. zwischen den Medienbereichen oder zwischen den Interaktionsfeldern.

Dies kann in diesem Rahmen nicht geleistet werden. Von daher bleibt die Darstellung eher statisch und - da auch die Differenzierung von nationalen Mediensystemen unterbleibt - in hohem Maße auf Deutschland begrenzt.
} 
Abbildung 2

Spezielles Modell: Teilbereiche der Medienpolitik

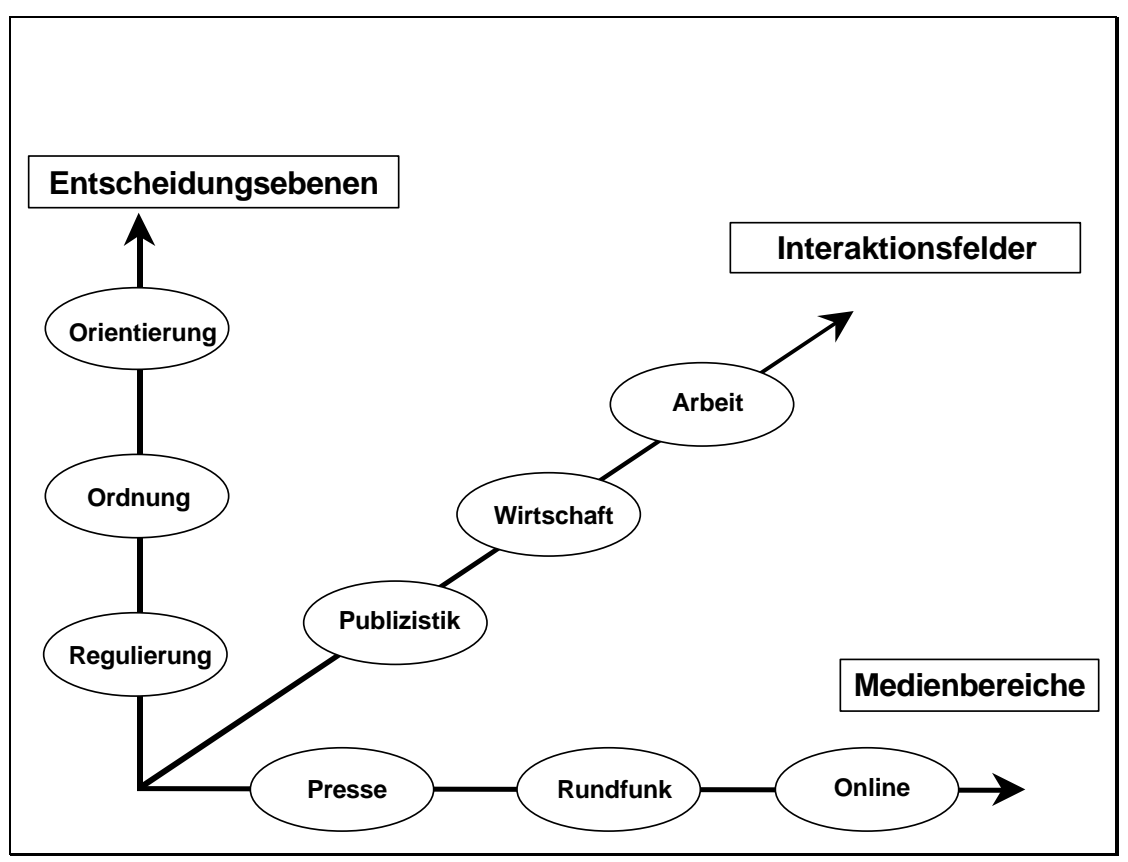

Die Differenzierung medienpolitischer Teilbereiche erfolgt durch eine Dimensionierung der Medienpolitik. Statt einer dem adäquaten parallelen Darstellung müssen die Befunde zu den einzelnen Teilbereichen im folgenden sequentiell referiert werden. Auf diese Weise werden Teilbereiche der Medienpolitik analytisch aufgeschlossen und der Handlungsraum der Medienpolitik modelliert. ${ }^{28}$

${ }^{28}$ Innerhalb der einzelnen Teilbereiche kann wieder mit der Unterscheidung von Akteur, Inhalt und Prozeß gearbeitet werden. 


\section{Differenzierung von Interaktionsfeldern: Publizistik, Wirtschaft, Arbeit}

Eine erste Differenzierung ist erforderlich im Hinblick darauf, welche kommunikativen

Beziehungen mit Regelsetzungen strukturiert werden. In erster Linie sind dies: ${ }^{29}$

- die Beziehungen zwischen politischen Organisationen und Medienorganisationen auf dem Markt politischer Meinungsbildung (dazu: 4.1)

- die Beziehungen auf den medienwirtschaftlich relevanten Märkten (dazu: 4.2)

- die Beziehungen innerhalb der Medienorganisationen (dazu: 4.3).

\subsection{Regulierung der publizistischen Beziehungen: Regeln für die Konkurrenz um Einfluss auf die politische Meinungsbildung}

Geprägt ist die medienpolitische Regulierung insgesamt von ihrer publizistischen Komponente, also den Regeln mit Blick auf die Bildung öffentlicher Meinung. Im Mittelpunkt stehen dabei politische Probleme und Interessen - sie geben der Publizistik ihre Brisanz und drängen andere Themenbereiche wie Wirtschaft, Kultur oder Sport an den Rand. Mit medienpolitischen Regulierungen werden die Bedingungen festgelegt, die eine Beziehung zwischen den beiden wichtigsten Akteurstypen in der politischen Kommunikation, den politischen Organisationen ${ }^{30}$ und den Medienorganisationen ${ }^{31}$ begrenzen, diesen Akteuren also zugleich Möglichkeiten eröffnen und ausschließen.

\subsubsection{Grundlage der publizistischen Beziehungen: Wettbewerb um Aufmerksamkeit}

Was ist der Kern dieser Beziehung? Politische Organisationen stehen im Wettbewerb um politische Machtpositionen. In einem demokratischen System sind einige zentrale Machtpositionen an den Gewinn von Mehrheiten bei den Bürgern gebunden. Die politischen Akteure konkurrieren also in den verschiedenen Arenen um die Zustimmung der Bürger. Im Gegenzug konkurrieren die Bürger um Vorteile, die ihnen in ihren verschiedenen Rollen aus politischen Entscheidungen erwachsen.

Wer die Zustimmung von Wählern gewinnen will, muss erst einmal ihre Aufmerksamkeit auf seine Botschaften lenken. Folglich konkurrieren die politischen Akteure um die

\footnotetext{
${ }^{29}$ Wenn ein bestimmter Aspekt eines Mediums politisch relevant wird, entsteht ein spezifisches Regulierungsfeld. So ist der ökologische Aspekt von Medien bislang nur von geringer politischer Bedeutung, allenfalls noch für die Presse.

${ }^{30}$ Unter politische Organisationen sind vor allem Parteien, Verbände und Gebietskörperschaften zu verstehen, die in unterschiedlichen Rollen agieren, vor allem als politische Kommunikationsakteure und als Regulierungsakteure.

${ }^{31}$ Unter Medienorganisationen sind vor allem Verlage, Rundfunk- und Internetanbieter, des weiteren Agenturen, Inserenten und Rechteanbieter zu verstehen - ebenfalls in verschiedenen Rollen.
} 
knappe Ressource Aufmerksamkeit ${ }^{32}$ derjenigen, von deren Zustimmung bzw. Unterstützung ihre jeweilige politische Machtposition abhängig ist: die Wählerschaft oder die Parteimitgliedschaft oder die Belegschaften in einer Branche oder die Versicherten - je nachdem, welche Positionen zu besetzen sind. Die Konkurrenz um Aufmerksamkeit ist scharf - nicht nur zwischen den politischen Organisationen, auch zwischen ihnen und den Anbietern von nicht-politischen Kommunikaten, wie z. B. Unterhaltungsangeboten oder Sportinformation. Bei den Anbietern von Aufmerksamkeit, den Rezipienten, kann man davon ausgehen, dass sie Nutzen und Kosten der verschiedenen Angebote kalkulieren und vergleichen. Was nützt ein bestimmtes Informationsangebot und was kostet es in monetärer, zeitlicher und kognitiver Hinsicht? Da der einzelne Wähler davon ausgehen kann, dass seine individuelle Entscheidung einen relativ geringen Einfluss darauf hat, wer in welche Machtposition gelangt, ist es aus Sicht des einzelnen Wählers rational, die Investitionen in die Wahlentscheidung und ihre kognitive Grundierung im Vergleich zu anderen Entscheidungen gering zu portionieren. Der durchschnittliche Bürger nimmt nur in dem Maße Informationen auf, wie die Kosten ihrer Beschaffung und Verarbeitung den erwarteten Nutzen aus der Entscheidung nicht übersteigen. Sein Handeln ist geprägt von „,rationaler Ignoranz “33. Damit stehen die politischen Akteure vor einem Problem: Ihr Interesse ist es, die Aufmerksamkeit der Bürger in einem möglichst hohen Maße zu gewinnen; im Interesse der Bürger liegt es aber, die Aufmerksamkeit mehr den Dingen zuwenden, von denen für sie persönlich mehr abhängt. Folglich versuchen politische Organisationen die Aufmerksamkeit dadurch zu gewinnen, dass sie Alarmsignale aussenden oder indem sie am unmittelbaren Nutzen einzelner Gruppen anknüpfen oder indem sie Informationen anbieten, die die Komplexität der Wahlentscheidung verringern und schnelle Entscheidungen ermöglichen, etwa durch das Charisma ihres Kandidaten.

Im Wettbewerb um Aufmerksamkeit für politische Botschaften bieten die Medien unschätzbare Vorteile. Vor allem bieten sie die Erreichbarkeit von denjenigen, die an Politik wenig interessiert sind oder die zwar interessiert sind, aber die Botschaften der politische Organisationen für wenig glaubwürdig halten. Durch Einbinden von politischen Botschaften in Informations- und Unterhaltungsformate kann diese zweifache Aufmerksamkeitsschwelle unterlaufen werden. Voraussetzung dafür ist eine Tauschbeziehung zwischen den Akteursgruppen. Medienorganisationen verfolgen je nach Organisations-

${ }^{32}$ Dazu Franck 1998. 
struktur eine Strategie der Gewinn - oder der Budgetmaximierung (Williamson 1990). Sie bieten Publizität - die Aufmerksamkeit eines Publikums - und fragen attraktive Inhalte nach. Politische Organisationen bieten Nachrichten - Botschaften, die Aufmerksamkeit bringen könnten wie Überraschungen und Skandale - und konkurrieren um Publizität. Folglich generieren sie Botschaften, die besser als die der politischen Konkurrenz auf die mediale Nachfrage zugeschnitten sind, und lassen sich in den Interaktionsprozessen auf die Spielregeln der Nachfrager ein. ${ }^{34}$

Beide Seiten sind an der Stabilität der Beziehungen interessiert: Es senkt die Kommunikationskosten, wenn Handeln der anderen Seite erwartbar wird. Stabilisierend wirken Regulierungen - der politische, oft auch rechtlich kodifizierte Teil des institutionellen Gerüsts. Die beiden Akteursgruppen sind nicht nur von Regulierung betroffen und an ihr interessiert, sondern auch an ihr beteiligt.

Die strategische Nutzung der Medienkommunikation durch die politischen Akteure wird mit Regulierung zugleich ermöglicht und begrenzt, und zwar im Hinblick auf die Beziehung zwischen politischen Organisationen und Medienorganisationen (dazu: 4.1.2) und im Hinblick auf die Beziehung zwischen den politischen Organisationen (da$\mathrm{zu}: 4.1 .3)$.

\subsubsection{Regulierung der Beziehung zwischen politischen Organisationen und Medienorganisationen}

Durch Regulierung wird der Einfluss der Politik insgesamt auf die Medien abgesichert, um die Medien als politisches Forum zu erhalten und den politischen Organisationen in ihrer Konkurrenz mit nicht-politischen Kommunikatoren ausreichende Publizität zu verschaffen. Zum einen wird durch medienpolitische Regulierung der Einfluss der politischen Akteure insgesamt auf die Medien abgesichert.

Dafür bietet der Rundfunkbereich die deutlichsten Beispiele. Zu nennen sind der Programmauftrag für den öffentlich-rechtlichen Rundfunk mit starkem politischpublizistischem Gewicht; die Kriterien für die Auswahl zwischen Bewerbern um Rundfunkfrequenzen; die Begrenzung der technischen Kapazitäten und der Entscheidungsprozeß über die Gebührenhöhe.

\footnotetext{
${ }^{33}$ Downs 1957; Frey/Kirchgässner 1994: 366ff.

${ }^{34}$ Dies kann hier nur holzschnittartig wiedergegeben werden. Vgl. dazu Jarren/Altmeppen/Schulz 1993; TheisBerglmair 1997. Selbstverständlich gruppieren sich um diesen Kern herum noch zahlreiche andere Beziehungsmomente, z. B. die Publizität als Waffe gegen andere politische Organisationen, etwa konkurrierende Parteigliederungen. Dabei wird jeweils Aufmerksamkeit des Publikums unterstellt, um das politische Ziel zu erreichen.
} 
Aber auch für die Presse sind Instrumente entwickelt worden, um den politischen Akteuren Einfluss zu sichern. So stellen ökonomische und rechtliche Unterstützungsmaßnahmen für die Presse auf deren publizistische Bedeutung ab und sichern die Publizitätschancen politischer Akteure, indem die Presse als vielfältiges politisches Forum erhalten bleibt.

Die politischen Organisationen sichern sich auf verschiedene Weise einen starken Stand gegenüber den Medienorganisationen und damit einen vergleichsweise günstigen Ausgangspunkt bei der Konkurrenz mit anderen Kommunikatoren um die knappe Ressource Aufmerksamkeit.

Andererseits wird durch Regulierung der Einfluss der Politik begrenzt: Den Medienorganisationen wird ein Spielraum garantiert, dessen Grenzen zeitlich, sachlich und sozial variabel sind. ${ }^{35}$ Von daher wird durch Regulierung sowohl die Autonomie als auch die Heteronomie der Medien verhindert. Die Regulierung lässt den politischen Einfluss um ein akzeptables Maß oszillieren. Dies wird strukturell dadurch gesichert, dass in kooperativen Arrangements zwischen Medienorganisationen und politischen Organisationen über Regulierungen entschieden wird. Die Regelung der Interdependenz von Politik und Medien beruht auf einer Selbstbindung der politischen Akteure (z. B. als gesetzlich garantierte „Staatsfreiheit“"). Abgesichert wird dies durch die Koppelung zum Recht; unabhängige Gerichte sollen die Einhaltung von Grenzen politischen Einflusses garantieren. Die verbinden mit dieser Aufgabe ihrerseits eigene Organisationsinteressen, die sich aber mit denen der politischen Organisationen und der Medienorganisationen nur in geringem Maße überschneiden.

\footnotetext{
${ }^{35}$ Für eine Erklärung der relativen Autonomie der Medien müssen mehrere Komponenten verknüpft werden: Historisch war die Emanzipation der bürgerlich-liberalen Bewegung an eine Vergrößerung des Spielraums ihrer eigenen Medien gegenüber dem Staat gebunden. Dann haben diese Medien als Organisationen Partikularinteressen ausgebildet, die eine entscheidende Triebfeder zur weiteren Vergrößerung des Spielraumes darstellen. Zum dritten liegt der Autonomisierung der Medien ein Interesse bei den politischen Organisationen insgesamt zugrunde: Zwar versuchen einzelne politische Organisationen, ihren partikularen Einfluß zu vergrößern, aber es liegt im langfristigen Interesse der politischen Organisationen insgesamt, den Medienorganisationen insgesamt ein hohes Maß an Autonomie zuzugestehen, da anderenfalls die Glaubwürdigkeit der Medien bei den Publika auf dem Spiel stünde und dann die Vorteile der medialen Kommunikation bei der Gewinnung von Aufmerksamkeit riskiert würden.
} 


\subsubsection{Regulierung der Beziehung zwischen politischen Organisationen}

Weiterhin wird durch medienpolitische Regulierung verhindert, dass der Einfluss eines einzelnen politischen Akteurs oder einer Akteursgruppe übermächtig wird. Vor allem die beiden großen Parteien halten sich wechselseitig in Schach. Durch medienpolitische Arrangements bleiben die Publizitätschancen auch der Oppositionspartei(en) gewahrt. Eine an die Regierung gekommene Partei wird nicht durch Regulierung den Zugang der Regierung zu den Medien derart verbessern, dass sich die Möglichkeiten der Opposition dramatisch verschlechtern. Denn in einem demokratischen System wird sie die Möglichkeit ihrer Abwahl in Rechnung stellen und nicht das Risiko eingehen, sich selbst für die Zukunft völlig chancenlos zu stellen - ein wichtiger Anreiz für den ,kooperativen Föderalismus“(vgl. Große Holtforth 2000: 121,146). Bei diesen Arrangements ist zu erwarten, dass die beiden großen Parteien Verträge zu Lasten Dritter machen, z. B. von sozialen Bewegungen oder von randständigen Parteien. Auf diese Weise haben sich Asymmetrien entwickelt. Einzelne Akteurstypen haben ihren Medieneinfluss gegen andere sichern und ausbauen können - so die Parteien im Vergleich zu den Verbänden. Aber auch da fungieren Instanzen des Rechts als Korrektive, die grobe Verstöße gegen Chancengleichheit ahnden.

\subsection{Regulierung der wirtschaftlichen Beziehungen: Regeln für die Medienmärkte}

Mit Regulierungen werden außerdem die Bedingungen auf den verschiedenen Medienmärkten festgelegt. Auf dem Rezipientenmarkt konkurriert eine rasch wachsende Fülle von Medienangeboten. Presse-, Rundfunk- und Onlineanbieter müssen sich so weit wie möglich an den Präferenzen der Rezipienten ausrichten, wenn sie deren Aufmerksamkeit auch nur in kleinen Portionen auf sich ziehen wollen. Die Anbieter finanzieren die Angebote vor allem dadurch, dass sie die akquirierten Publika als quantitativ und qualitativ bestimmte Zielgruppen - bzw. deren Aufmerksamkeit - auf dem Inserentenmarkt an Inserenten verkaufen. Auf der anderen Seite konkurrieren Medienorganisationen auf dem Rechtemarkt, um Nutzungsrechte von denjenigen zu erwerben, die attraktiven Programmrohstoff anbieten. Um die Investitionsentscheidungen der Medienorganisationen konkurrieren Gebietskörperschaften auf dem Standortmarkt und bieten günstige Bedingungen an. 
Alle diese wirtschaftlichen Beziehungen - Programme gegen Aufmerksamkeit, Zielgruppen gegen Werbeentgelte, Eigentumsrechte gegen Entgelt, Investitionen gegen Unterstützung - wurden und werden im Vergleich zu anderen wirtschaftlichen Beziehungen intensiv reguliert. Dies gilt besonders für Rezipientenmärkte: Beispiele sind die Regeln für Werbung, Jugendschutz, Urheberrechte, Verbraucherschutz usw. Dabei verbinden sich die Interessen der Marktteilnehmer an stabilisierenden Regelungen mit den Eigeninteressen von Regulierungsbehörden, Selbstkontrolleinrichtungen usw.

Da die Medienorganisationen eine Vermittlungsposition zwischen Rezipienten und politischen Organisationen einnehmen und auf beiden Seiten in Tauschbeziehungen stehen, ist ihr Handeln auch zweifach von Regulierungen bestimmt.

\subsection{Regulierung der Arbeitsverhältnisse: Regeln für die Beziehungen in den Medienorganisationen}

Über die Arbeitsbeziehungen in den Medienorganisationen spannt sich ein engmaschiges Netz von Regeln: manche sind auf Verbandsebene, manche staatlich entstanden; manche sind rechtlicher, manche informeller Natur; manche haben Geltung für alle Medienbereiche, manche für einen einzelnen. Diese Regeln strukturieren die Konflikte der Akteure über die Bedingungen der Arbeitsprozesse.

Im Hinblick auf betriebliche Mitbestimmung sind mit einer publizistischen Begründung („Tendenzschutz“) den Interessenvertretungen von Beschäftigten in Medienorganisationen im Vergleich zu anderen Branchen reduzierte Rechte zugestanden worden trotz nachhaltigen Widerstands.

Im Zusammenhang damit sind in den 60er und 70er Jahren langwierige Auseinandersetzungen um die Autonomie von Redaktionen gegenüber Verlagsleitungen geführt worden (,innere Pressefreiheit"“), die vor allem zu einer Abgrenzung publizistischer Kompetenzen geführt haben (,Richtlinien-“, „,Grundsatz-“ und „Detailkompetenz“).

Nicht nur bei der Regelung von Tariffragen (Vergütung und Arbeitszeiten), der ureigenen Domäne von Verbänden, wird vor allem bei der Presse deutlich, dass starke Verbände das Feld beherrschen, die vergleichsweise viel selbst regulieren und dabei innerhalb eines weit gesteckten staatlichen Rahmens agieren (Roloff 1994). Auch bei der Absicherung für den Risikofall (Sozialpolitik) spielen sie eine gewichtige Rolle, und selbst die Ausbildung wurde lange Zeit ausschließlich auf der betrieblichen Ebene verantwortet - reguliert durch Vereinbarungen der Tarifpartner. Das gleiche Bild in der 
Standespolitik: die Verbände entscheiden über die Zugehörigkeit zur journalistischen Profession. 


\section{Differenzierung von Medienbereichen: Presse, Rundfunk, Online}

So weit die Differenzierung der Regulierung nach der Art von Beziehungen zwischen Kommunikationsakteuren. Es ist bei den angeführten Beispielen deutlich geworden, dass eine weitere Differenzierung erforderlich ist. Denn die Akteurskonstellationen und die Schwerpunkte der Regulierung unterscheiden sich so sehr von Medienbereich zu Medienbereich, dass von abgrenzbaren Teilbereichen der Medienpolitik gesprochen werden kann. Der Presse-, der Rundfunk- und der Onlinepolitik kommt unter all den Medienpolitiken besondere Bedeutung zu. ${ }^{36}$

\subsection{Pressepolitik in Deutschland: Konstanz und Konsens an der medien- politischen Peripherie}

\subsubsection{Regulierung der Presse als einem publizistischen Faktor}

Unter dem Gesichtspunkt der Presse als einem publizistischen Faktor geht es in erster Linie um die Beziehungen zwischen politischen Organisationen, die daran interessiert sind, via Presse ihren Einfluss auf die öffentliche Meinung geltend zu machen, und den Presseorganisationen, die daran interessiert sind, ihre publizistische Unabhängigkeit zu wahren. In dem Maße, wie die partei- und verbandseigene Presse an Bedeutung verliert, nehmen die Anstrengungen der politischen Organisationen zu, über die unabhängige Presse Einfluss auf die öffentliche Meinung zu nehmen. Pressepolitische Regulierung ermöglicht bestimmte Formen und schließt andere aus. Vor allem sichert sie einen Spielraum der Presseunternehmen gegen staatliche Eingriffe.

Normative Grundlage der Regulierung bildet die Zuweisung einer öffentlichen Aufgabe. Die Presse soll nicht nur der individuellen Meinungsäußerung dienen, sondern zudem auch der kollektiven Meinungsbildung. Auf dieser politischen Funktionszuweisung

\footnotetext{
${ }^{36} \mathrm{Zu}$ der jeweiligen Regulierungslage im einzelnen siehe die Beiträge von Stöber, Beck, Rössler und Schulz/Jürgens in Bentele/Brosius/Jarren 2002. Bei der Pressepolitik steht die Tageszeitung im Mittelpunkt, bei der Rundfunkpolitik das Fernsehen und bei der Onlinepolitik das World Wide Web (WWW). Die Politik im Hinblick auf Film, Buch, Tonträger usw. wird im folgenden nicht behandelt, da die Schwerpunkte in der Medienpolitik nach der publizistischen Bedeutung gesetzt werden. Der Darstellung liegt eine Systematik nach Ansatzpunkten der Regulierung zugrunde (Regulierung der Teilnehmer, der Inhalte und der Prozeduren der Kommunikation; vgl.Kopper/Rager 1993). Implizit werden die Teilbereiche der Medienpolitik dann noch nach einem strategischen Gesichtspunkt differenziert und zwischen regulativen (Ge- und Verbote), performativen (staatliche Leistungen), ökonomischen (An- und Abreize) und kommunikativen (positive und negative Beeinflussung) Instrumenten unterschieden (die leitende Unterscheidung bei Jarren 1998: 617). Innerhalb der Medienbereiche können Regulierungen auf einzelne Phasen des Kommunikationsprozesses spezifiziert werden (Informationsbeschaffung, Medienproduktion, Distribution, Rezeption). Im folgenden werden allein die deutschen Regulierungsverhältnisse dargestellt. Ein internationaler Vergleich kann ebensowenig geleistet werden wie die Einbettung in den historischen Kontext.
} 
basiert eine Reihe von Regelungen, die das Handeln der Akteure in den einzelnen Phasen des Kommunikationsprozesses strukturieren.

Zunächst zur Informationsbeschaffung: Der Nachrichtenselektion kommt eine Schlüsselfunktion im Prozess der politischen Kommunikation zu. Die Möglichkeit, dass ein einzelnes Medienunternehmen oder ein einzelner politischer Akteur diese Schlüsselstellung okkupiert, wird dadurch ausgeschlossen, dass die führende deutsche Nachrichtenagentur als eine Genossenschaft der Verleger gegründet wurde, die zudem im Wettbewerb mit weltweit agierenden Agenturen steht. Im Hinblick auf die journalistische Recherche wird durch rechtliche Regelungen der Spielraum der Journalisten gegen staatliche Eingriffe geschützt; Quellenschutz durch das Zeugnisverweigerungsrecht und Privilegierung der Journalisten bei behördlichen Auskünften sind Beispiele dafür und für die Auseinandersetzungen darum. Im Gegenzug wird den Journalisten in den Landespressegesetzen eine Sorgfaltspflicht als Norm für die Informationsbeschaffung auferlegt. Ihr zufolge sind die Nachrichten vor der Publikation ,,mit der äußersten, nach den Umständen gebotenen Sorgfalt“ zu prüfen. Allerdings wird eine Verletzung nicht unter Strafe gestellt, sondern hat über eine mögliche Gegendarstellung von Betroffenen hinaus allenfalls zivilrechtliche Konsequenzen. Voraussetzung dafür ist die Transparenzpflicht. Die staatlichen Rahmenregelungen für die Recherche sind durch selbstregulative Vorkehrungen ergänzt worden (in Gestalt des Presserats, der bei Verstößen gegen den Pressekodex Rügen erteilen kann).

Im Gegensatz zum journalistischen Bereich ist die Öffentlichkeitsarbeit bislang weitgehend ohne spezifische Regulierung geblieben - ein durch die Meinungsfreiheit geschützter Spielraum der politischen Akteure, den sie dafür nutzen, Einfluss auf die öffentliche Meinung zu nehmen. Eine Ausnahme bildet die Öffentlichkeitsarbeit staatlicher Instanzen, insbesondere in der Grauzone von Parteienwahlkampf und Regierungsdarstellung (vgl. Hofsähs 1994).

Im Hinblick auf die Presseproduktion ist gesetzlich garantiert, dass jeder ein Pressemedium dem Publikum anbieten darf, ohne die Genehmigung durch eine staatliche oder außerstaatliche Instanz einholen zu müssen (Lizenzfreiheit). Soll jemandem der Zugang zum Publikationsmarkt untersagt werden, sind dafür hohe Hürden zu überwinden (z. B. ein Parteiverbot durch das Bundesverfassungsgericht). 
Und spätestens seit der „Spiegel-Affäre“ 1962 sind auch staatliche Eingriffe in die Inhalte politischer Berichterstattung an enge Bedingungen gebunden (etwa zum Schutz des inneren Friedens oder bei Verunglimpfung des Staates). Desgleichen bei nichtpolitischen Presseinhalten: Neben dem Verbot von exzessiven Gewaltdarstellungen und von pornographischen Darstellungen sind der Schutz der Persönlichkeit von Objekten der Berichterstattung (mit der Möglichkeit der Gegendarstellung bei unrichtigen Tatsachenbehauptungen), der Schutz von Minderheiten (bis zur Ausdehnung des Straftatbestandes der Beleidigung auf Gruppen) und der Schutz der Privatsphäre z. T. heftig umstrittene Grenzziehungen für die Presse. Andererseits ist mit dem grundgesetzlichen Verbot einer staatlichen Vorzensur eine Schranke gesetzt, die der Staat auch bei einem akzeptierten Schutzgut nicht überschreiten darf.

Vorschläge, die Pressedistribution analog zur Nachrichtenagentur genossenschaftlich bzw. gemeinwirtschaftlich zu lösen, konnten sich nicht durchsetzen. Abgesehen von Steuervergünstigungen wird der Pressevertrieb mittlerweile weitgehend dem Markt überlassen - und damit den generellen Regulierungen für die Koordination von Angebot und Nachfrage.

Die Presserezeption bleibt weitgehend unreguliert - zumindest im Bereich der politischen Kommunikation. Für andere Mediensegmente werden mit Blick auf den Jugendschutz die Zugänge zur Rezeption für bestimmte (Alters-)Gruppen reglementiert. ${ }^{37}$

Dies alles fügt sich zu einem Profil der publizistischen Regulierung in der Bundesrepublik Deutschland: Das politische Moment der Presse wird mit der Regulierung zu stärken versucht. Der Pressekommunikation werden rechtlich gestützte Grenzen gesetzt; vieles, aber nicht alles wird der Selbstregulation überlassen. Dies kontrastiert scharf mit traditioneller pressepolitischer Praxis: Eine staatliche Steuerung von Zugang, Inhalt und Prozeduren von der Informationsbeschaffung über Presseproduktion und Distribution bis zur Rezeption kann als Option nur noch an vergangenen Epochen vom Absolutismus bis zum DDR-Sozialismus studiert werden.

\footnotetext{
${ }^{37}$ Bei der Kinderpornographie ist mittlerweile auch der Besitz unter Strafe gestellt ( $\$ 184$ Abs. 5 StGB).
} 


\subsubsection{Regulierung der Presse als einem Wirtschaftsgut}

Durch pressewirtschaftliche Regulierung werden Regeln für die Beziehungen auf den Pressemärkten gesetzt. Maßgebend sind die im engeren Sinne wirtschaftlichen Interessen, die sich mit Pressekommunikation verbinden. Neben die Regulierungen, die für alle Wirtschaftsprozesse gelten, wie das Verbot unlauteren Wettbewerbs oder die Vorschriften für Unternehmensbilanzen, treten spezifische Regulierungen für die Pressewirtschaft.

Ausgangspunkt ist die eigentumspolitische Grundsatzentscheidung, die Presse sich privatwirtschaftlich organisieren zu lassen, ihr aber gesetzlich eine „öffentliche Aufgabe“ zuzuweisen.

Der Wettbewerb zwischen Presseunternehmen, von dem die Sicherung der publizistischen Vielfalt erwartet wird, ist erheblich beeinträchtigt: Im Bereich der Tageszeitungen finden seit langem praktisch keine Marktzutritte statt, und es sinkt die Zahl der unabhängigen Verlage und der „Publizistischen Einheiten“38. In Folge einer intensiven öffentlichen Diskussion in den 60er Jahren hat der Bund das kartellrechtliche Instrument der Fusionskontrolle speziell für die Presse verschärft: Bereits ein Zusammenschluss von Presseunternehmen mit einem gemeinsamen Umsatz von 50 Mio. DM - im Unterschied zu einer Milliarde DM in anderen Branchen - ist beim Bundeskartellamt anzeigepflichtig, das eine Fusion untersagen oder an Auflagen knüpfen kann, wenn eine über Marktanteile definierte - marktbeherrschende Stellung entsteht oder verstärkt wird. Im Schatten dieser rechtlichen Regelung haben sich Kooperationsformen der Presseunternehmen unterhalb der Schwelle der Fusion (Marktabgrenzung, gemeinsame Infrastruktur) und informelle Verfahren der Abstimmung zwischen Kartellbehörden und Presseunternehmen - unter Vermittlung der Verbände - etabliert. Im Kartellrecht ist außerhalb der Fusionskontrolle nur die Möglichkeit gegeben, den ökonomischen Missbrauch einer marktbeherrschenden Stellung (z. B. bei der Preisgestaltung) zu unterbinden, nicht aber gegen die marktbeherrschende Stellung selbst vorzugehen. ${ }^{39}$

\footnotetext{
${ }^{38}$ Vgl. Stöber 2000, Schütz 1999.

${ }^{39}$ Bei einer der letzten großen pressepolitischen Herausforderungen, der Neuordnung der Presselandschaft in den neuen Ländern nach 1989, hat die Treuhandanstalt als das Entscheidungszentrum weitgehend nach wirtschaftlichen Kriterien entscheiden; publizistische Kriterien spielten eine geringe Rolle.
} 
Geringere Bedeutung hat die strukturpolitische Regulierung. Die Subventionierung der Presse beschränkt sich auf einige Steuervergünstigungen und ist im Vergleich zu anderen Ländern und zu anderen Branchen zurückhaltend. Wichtiger für die Presseverlage sind rechtliche Schutzvorkehrungen gegen Konkurrenten auf dem Werbemarkt wie den Anzeigenblättern und den Gratiszeitungen. Auch dadurch ist es bislang weitgehend gelungen, ausländische Anbieter vom deutschen Pressemarkt fernzuhalten, während deutsche Anbieter vor allem auf osteuropäischen Märkten stark vertreten sind. Noch wichtiger für die Presse sind die territorialen und zeitlichen Beschränkungen der Werbezeit beim Rundfunk, während umgekehrt die Hürden für eine Beteiligung der Verleger am Rundfunk niedrig gelegt waren.

\subsubsection{Fazit: Pressepolitik - vom Zentrum an den Rand der Medienpolitik}

Schaut man sich die Agenda ${ }^{\mathbf{4 0}}$ der Pressepolitik im Zusammenhang an, so wird deutlich, in welchem Maße das publizistisch-politische Moment die pressepolitische Regulierung insgesamt prägt. Auch die Fragen der Mitbestimmung (,Tendenzschutz“) oder der Wettbewerbssicherung sind publizistisch aufgeladen, d. h. von der Sorge geprägt, dass ein bestimmter politischer Akteur sich dadurch besonderen Einfluss auf die Presse sichern könnte. Folglich wird mit Regulierung versucht, derartige Vorteile vor allem durch rechtliche Schranken zu verhindern. Hier greifen die oben dargelegten strategischen Interessen der politischen Organisationen: Sicherung von Publizitätschancen für die politischen Akteure insgesamt durch Erhaltung der Presse als einem vielfältigen politischen Forum und Verhinderung der Dominanz einzelner politischer Akteure in der Presse insgesamt.

In der Arena ${ }^{41}$ der Pressepolitik setzen sich die pressepolitischen Akteure über das $\mathrm{Ob}$, das Was, das Wann, das Wer und das Wie der Regulierung auseinander. In dieser Konstellation sind die beiden großen Parteien von besonderem Gewicht; den Gegenpol bilden die Verlegerverbände und die medienrelevanten Gewerkschaften, die in keinem Medienbereich ein so starkes Gewicht haben wie hier und sich in Gremien der Selbstre-

\footnotetext{
${ }^{40}$ Unter „Agenda“ wird die nach Prioritäten geordnete politikfeldspezifische Sammlung von Problemen verstanden, bei denen kollektiv bindende Entscheidungen zu treffen sind.

${ }^{41}$ Unter „Arena“ wird die politikfeldspezifische Konstellation von Akteuren verstanden, die sich über die kollektiv bindenden Entscheidungen auseinandersetzen und die je nach Kompetenz unterschiedlichen Anteil an der Entscheidung haben. Die Akteure in der Arena werden beobachtet von der Öffentlichkeit auf der Galerie, wobei gerade in der Medienpolitik einige Teile dieser Öffentlichkeit selbst wiederum Partei sind.
} 
gulation (z. B. dem Presserat) routiniert miteinander auseinandersetzen - nicht nur über Tarif-, Ausbildungs- und standespolitische Fragen. Auch deswegen hat der Bund seine presserechtliche (Rahmen-)Gesetzgebungskompetenz nicht wahrgenommen und dieses Feld weitgehend den Ländern überlassen. Von Gerichten werden Präzedenzentscheidungen gefällt, denen regulative Bedeutung zukommt. Da die Pressewirtschaft bislang relativ stark national ausgeprägt war, konnte auch die EU-Kommission aus der Regulierung herausgehalten werden.

Insgesamt agieren die staatlichen Instanzen also im Pressebereich sehr zurückhaltend. Das Netz der Pressepolitik ist aus vielen Knoten geknüpft - einige davon sind staatliche Akteure.

Mittlerweile ist die Pressepolitik in Agenda und Arena geprägt von Konstanz und Konsens, von Routine und Arrangement. Sie hat erheblich an politischer Brisanz verloren und ist an die Peripherie der Medienpolitikgerückt (vgl. Jarren 1998: 623).

\subsection{Rundfunkpolitik in Deutschland: Detaillierte Regulierung - intensive Konflikte}

Sehr viel stärker als die Presse wird der Rundfunk reguliert

- wer als Anbieter an der Rundfunkkommunikation teilnehmen darf und wer nicht;

- was Inhalt von Rundfunkkommunikation sein darf und was nicht;

- $\quad$ wie Rundfunkkommunikation ablaufen darf und wie nicht. ${ }^{42}$

\subsubsection{Wer? Regulierung der Teilnahme an der Rundfunkkommunikation}

Wer Rundfunk anbieten darf und wie die Anbieter zueinander stehen, ist genau geregelt. ${ }^{43}$ Grundlage dafür sind die ersten drei Rundfunkurteile des BVerfG von 1961, 1971 und 1981, ${ }^{44}$ das auf der Basis eines publizistischen Verständnisses von Rundfunk (Funktion: Bildung öffentlicher Meinung) das Spektrum der Anbieter festgelegt hatte: die öffentlich-rechtliche Form der Rundfunkanbieter wird vorgezogen, die privatkommerzielle hingenommen und die staatliche ausgeschlossen. ${ }^{45}$

\footnotetext{
${ }^{42}$ Die meisten Vorschriften sind im Rundfunkstaatsvertrag (im folgenden RStV) niedergelegt, einem von den Bundesländern gemeinsam beschlossenen und mehrfach veränderten Regelwerk.

${ }^{43}$ Die Regulierung der Teilnahme an der Rundfunkrezeption kann nur noch an historischen Beispielen studiert werden.

${ }^{44}$ BVerfGE 12, 205; 31, 314; 57, 295.

${ }^{45}$ Vgl. Heinrich 1999: 86. Mit diesem Urteil wurden zugleich die Kompetenzen festgelegt: die Länder haben den Rundfunk zu gestalten, nicht der Bund (siehe dazu 6.1.2).
} 
Nach zähem Ringen einigten sich die rundfunkpolitischen Hauptakteure - Landesregierungen, die beiden großen Parteien und Medienorganisationen - 1984 darauf, diesen Rahmen durch ein „Duales Rundfunksystem“ auszufüllen, mit dem öffentlichrechtliche und privat-kommerzielle Rundfunkanbieter in ein geregeltes Verhältnis gestellt werden.

Öffentlich-rechtliche Anbieter (ÖRA) sind weder Behörden noch Unternehmen. Sie werden durch ein (Landes-) Gesetz begründet, erfüllen aber die ihnen gesetzte „öffentliche Aufgabe" in Eigenverantwortung. Mit dieser Konstruktion wird in Abkehr von der deutschen Tradition Rundfunk öffentlich, aber nicht staatlich organisiert und eben dies staatsrechtlich garantiert (vgl. Jarren/Schulz 1999: 118).

Die föderale Struktur des Rundfunks kommt dadurch zum Ausdruck, dass sie als Landesrundfunkanstalten organisiert sind und sich auf einzelne oder mehrere Bundesländer beziehen. ${ }^{46}$ Umstritten ist der Zuschnitt der ÖRA. Bislang haben selbst Bremen, Berlin, Brandenburg und das Saarland an eigenständigen Landesrundfunkanstalten festhalten können - nicht nur aus standortpolitischen Gründen. Andererseits haben sich SWF und SDR zum Südwestdeutschen Rundfunk zusammengeschlossen und damit ihren Stellenwert innerhalb der öffentlich-rechtlichen Rundfunklandschaft erhöht. Aus der föderalen Struktur folgt, dass die ARD als eine Kooperationsform mit schwacher Zentrale konzipiert wurde. Hauptaufgabe ist die Koordination eines gemeinsamen Fernsehprogramms der Landesrundfunkanstalten. Das öffentlich-rechtliche Gegenstück dazu wurde mit dem ZDF konstruiert - ein von Mainz aus national operierender Fernsehanbieter, dessen Rechtsgrundlage ein Staatsvertrag aller Bundesländer bildet.

In den Rundfunkgesetzen ${ }^{47}$ wird die Binnenstruktur der Anstalten durch eine Definition der Organe geregelt. In ihrem Mittelpunkt steht jeweils der Rundfunkrat - das Gremium, durch das die politischen Organisationen - in erster Linie Parteien und Verbände vielfältigen Einfluss auf die Rundfunkanstalten nehmen können sollen. Im jeweiligen Rundfunkgesetz ist geregelt, welche Organisationen Vertreter in den Rundfunkrat entsenden. Seine Zusammensetzung ist an einem ständischen Modell orientiert: Vertreter von organisierten gesellschaftlichen Interessen sind in der Mehrheit gegenüber Vertretern von Fraktionen der jeweiligen Landtage bzw. von Regierungsvertretern. Der Anteil

\footnotetext{
${ }^{46}$ Beispiele sind der Hessische Rundfunk als Anstalt eines Bundeslandes und der Mitteldeutsche Rundfunk als Mehrländeranstalt.

${ }^{47}$ Darunter fasse ich immer Landesrundfunkgesetze für die Anstalten eines Bundeslandes und Staatsverträge für Mehrländeranstalten zusammen.
} 
der Parteipolitiker ist um so größer, je später eine Rundfunkanstalt gegründet wurde. ${ }^{48}$ Es wird davon ausgegangen, dass es vor dem BVerfG Bestand hätte, wenn der Anteil von Parlamentariern und Regierungsvertretern ein Drittel nicht übersteigt (Langenbucher 1999: 220). Nichtsdestoweniger sind die Rundfunkräte in hohem Maße parteipolitisch strukturiert: Es haben sich rote und schwarze „Freundeskreise“ gebildet, denen sich ein großer Teil der Mitglieder zuordnet - und über die vor allem eine konsequent am Parteienproporz orientierte Personalpolitik betrieben wird.

Der Rundfunkrat wählt und kontrolliert den Intendanten, der die Anstalt leitet und sich in der Geschäftsführung mit dem Verwaltungsrat abzustimmen hat, einem ebenfalls vom Rundfunkrat gewählten kleineren Gremium, in dem den Landesregierungen ein noch wesentlich stärkeres Gewicht zukommt.

Die Präferenz der Rundfunkpolitik für öffentlich-rechtliche Anbieter drückt sich in der lange Zeit rechtlich nicht geregelten bevorzugten Versorgung mit terrestrischen Frequenzen und bei der Rangfolge in der Belegung der Kabelkanäle aus (,must-carryrule“), die in den Landesmediengesetzen festgelegt ist (vgl. Eifert/Hoffmann-Riem 1999: 74ff).

Wer als privat-kommerzieller Anbieter (PKA) auf den Rundfunkmarkt treten darf, wird in einem geregelten Zulassungsverfahren politisch entschieden. ${ }^{49}$ Vor allem dafür sind die Landesmedienanstalten (LMA) gegründet worden - wiederum keine Behörden oder Unternehmen, sondern rechtlich eigenständige, durch einen Anteil an der Rundfunkgebühr finanzierte, von politischen Organisationen kontrollierte Organisationen mit föderalem Zuschnitt auf einer jeweils landesrechtlichen Rechtsgrundlage. Sie werden in hohem Maße von den Landesregierungen und den sie tragenden Parteien kontrolliert, und zwar vor allem über die Aufsichtsgremien und über die Besetzung des Leitungsorgans (vgl. Jarren/Schulz 1999: 126, 143). Sie vergeben nach publizistischen und ökonomischen Kriterien die für privat-kommerzielle Nutzung vorgesehenen terrestrischen Frequenzen für Anbieter im jeweiligen Bundesland bzw. für bundesweite Anbieter und sie regeln die Belegung der Kabelkanäle. ${ }^{50}$ Damit ist einmal eine Konkurrenzsituation um die Standortentscheidungen zwischen den LMA gegeben, andererseits ist die Ko-

\footnotetext{
${ }^{48}$ Vgl. die Zusammensetzung des „Fernsehrats“ beim ZDF: ZDF-StV: § 21 und Herrmann 1994: 291. Eine Mehrheit der Vertreter von Regierung und Parlament wird als nicht vereinbar mit der Staatsfreiheit angesehen. Aus dem gleichen Grunde ist die Wahl der Mitglieder des Rundfunkrates bei NDR und WDR durch die Länderparlamente abgeschafft und durch das Entsendemodell ersetzt worden. Zum Einfluß der Parteien siehe Kepplinger 1994: 123 m.w.N.

${ }^{49}$ Ausgenommen ist innerorganisatorischer Rundfunk („Business-TV“).

${ }^{50}$ Die Belegung der Satellitenübertragungskapazitäten entzieht sich deutscher Regulierung, da sie weitgehend in der Hand ausländischer Unternehmen sind.
} 
operation dadurch zwingend erforderlich, dass die in einem Bundesland zugelassenen Anbieter zumeist auch in allen anderen Bundesländern eine Frequenz bzw. einen Kabelkanal erhalten wollen.

Außerdem kontrollieren die LMA, ob die zugelassenen PKA die Rechtsvorschriften (z. B. Werbeanteil) und die Vereinbarungen (z. B. Informationsanteil) einhalten. ${ }^{51}$ Für die Durchsetzung von Regeln steht den LMA ein abgestuftes Sanktionspotential - vom Bußgeld bis zum Lizenzentzug - zur Verfügung; sie setzen aber schon aus Kapazitätsgründen stärker auf die Kooperativität der privaten Anbieter und auf entsprechend informelle Verfahren.

Für die Kooperation untereinander haben sie mittlerweile gemeinsame Richtlinie erarbeitet und eigene Gremien gebildet; dies wurde durch einige, auch gerichtsnotorische Auseinandersetzungen zwischen LMA über Ansiedlungen, Auflagen und Interpretationen von Vorschriften vorangetrieben (vgl. Jarren/Schulz 1999: 132f).

Besondere Bedeutung haben die LMA in Nordrhein-Westfalen und in Bayern, den Bundesländern mit dem höchsten Gebührenaufkommen und zugleich Sitzländern der beiden großen deutschen privaten Fernsehanbieter, der Kirch-Gruppe und der Bertelsmann AG.

Für die Kontrolle der Konzentration_und damit der Anbieterstruktur im privaten Fernsehen ist ein rundfunkspezifisches Instrumentarium entwickelt worden, das sich nicht auf Fusionskontrolle beschränkt. Dadurch ist es möglich, politisch nicht nur dann einzugreifen, wenn durch Fusionen Macht über den Markt gewonnen oder ausgebaut wird, sondern auch, wenn dies durch Erfolg am Markt geschieht. Die Kontrolle der Konzentration wurde nach einem langen Aushandlungsprozess 1996 neu gestaltet und weitgehend einer eigens dafür gegründeten zentralen Kommission aus Sachverständigen ${ }^{52}$ übertragen. Sie beobachtet die Marktanteile der Anbieter. Wenn ein Konzern mit allen ihm zurechenbaren Programmen insgesamt eine Marke von 30 - am Fernsehzuschauermarkt erreicht, werden ihm keine weiteren Programme mehr zugestanden. Außerdem soll dann einvernehmlich (z. B. Abgabe von Beteiligungen) oder notfalls durch Widerruf von Zulassungen dafür gesorgt werden, dass der Marktanteil unter die kritische Marke sinkt. ${ }^{53}$ Die Beschlüsse der Kommission sind für die jeweils zuständige LMA

\footnotetext{
${ }^{51}$ Außerdem organisieren sie einen offenen Kanal, also die Möglichkeit für Gruppen und einzelne Personen, eigene Sendungen zu produzieren und zu verbreiten, und fördern nicht-kommerzielle Anbieter.

52 „Kommission zur Ermittlung der Konzentration im Medienbereich“ (KEK).

${ }^{53}$ Die ursprüngliche Konzentrationsregelung für das private Fernsehen hatte noch das Prinzip der Begrenzung von Kapitalanteilen vorgesehen.
} 
bindend und können nur durch weitgehendes Einvernehmen aller LMA umgangen werden. ${ }^{54}$ Bislang bleiben beide großen privaten Fernsehanbieter knapp unter dieser Marke. Bereits bei dem Marktanteil eines Programms von 10 - ist vorgeschrieben, in einem genau festgelegten Umfang und Platzierung Sendezeit an unabhängige Anbieter abzugeben, um durch ein Fensterprogramm die Vielfalt des Vollprogramms zu erhöhen.

Entgegen den früher leitenden Vorstellungen von Außenpluralismus durch Wettbewerb und Binnenpluralismus durch Anbietergemeinschaften orientiert sich die derzeit gültige Regelung an einem Marktanteilsmodell. Damit wurde den großen deutschen PKA ein limitiertes Wachstum ermöglicht - mit Verweis auf den internationalen Wettbewerb. Im Gegenzug ist bislang weitgehend verhindert worden, dass ausländische Anbieter Zutritt zu den deutschen Medienmärkten erhielten. Dadurch blieb das Verhältnis zwischen Medienorganisationen und politischen Organisationen überschaubar und wechselseitiger Einfluss gesichert. Eine stärkere Internationalisierung hat sich hingegen mittlerweile bei dem Verkauf der Kabelnetze durch die Deutsche Telekom ergeben. ${ }^{55}$

Zwar hat sich auf EU-Ebene trotz einiger Anläufe keine rundfunkspezifische Kontrolle der Konzentration entwickelt, aber im Rahmen ihrer allgemeinen Wettbewerbspolitik ist die EU-Kartellbehörde auch im Medienbereich tätig geworden; so hat sie z. B. die Kooperation von Bertelsmann und Kirch beim digitalen Pay-TV unterbunden, vor allem um den Zugang für Anbieter von digitalen Programmen offen zu halten. Sie sah insbesondere durch die Monopolisierung der Technologie für Empfang, Navigation und Abrechnung den Wettbewerb gefährdet. Auch auf nationaler Ebene hat die Sicherung des offenen Zugangs zum digitalen Fernsehen einen hohen Stellenwert gewonnen, da die Bedeutung digitaler Plattformen für alle Formen medialer Kommunikation zunehmen wird. Anbieter von technischen Schnittstellen zum digitalen Fernsehen (,Set Top Box“) müssen nach deutschem Rundfunkrecht den Zugang für alle Anbieter von digitalen Programmen diskriminierungsfrei gestalten.

Zusammengefasst: Kern der Regulierung bildet im Rundfunkbereich eine gegenüber anderen Medienbereichen starke Kontrolle darüber, wer überhaupt als Anbieter auftreten darf. Des weiteren wird bei den ÖRA durch Regelungen zur Binnenstruktur und zur

\footnotetext{
${ }^{54}$ Vor allem dafür ist die Konferenz der Direktoren der LMA (KDLM) gegründet worden, während im Vergleich dazu die Kooperation auf der Ebene der Aufsichtsgremien schwach ausgeprägt ist (vgl. Jarren/Schulz 1999: 134).

${ }_{55} \mathrm{Am}$ anderen Ende des Spektrums wird mit zum Teil komplizierten landesspezifischen Regelungen versucht, den Verlegern die Beteiligung am lokalen Rundfunk zu ermöglichen, dabei aber zugleich örtliche Doppelmonopole zu verhindern.
} 
Finanzierung $^{56}$ der Einfluß politischer Organisationen gesichert. Bei den PKA wird politisch kontrolliert, in welchem Maße sich Oligopole bilden können.

\subsubsection{Was? Regulierung der Inhalte von Rundfunkkommunikation}

Die Rundfunkpolitik nimmt vielfältig Einfluß darauf, wie viele Programme und welche Art von Programmen gesendet und welche nicht gesendet werden dürfen. Dem Rundfunk als ganzem wird mehr noch als der Presse eine publizistische Aufgabe zugewiesen (,dienende Funktion“). Für die Bildung öffentlicher Meinung zu den Themen von allgemeinem Interesse soll umfassende Information geboten und die Vielfalt der Positionen zum Ausdruck gebracht werden. Dadurch bleiben die Publizitätschancen der politischen Akteure gewahrt.

Nicht alle Rundfunkanbieter haben dazu im gleichen Ausmaß Beiträge zu erbringen. Die ÖRA sind bevorzugt gehalten, die „Grundversorgung“ vor allem mit politischer Information in der gebotenen Gründlichkeit und Vielfalt zu sichern - so das BVerfG in seinem vierten und fünften Rundfunkurteil (BVerfGE 73, 118; 74, 297). Mit dieser Schlüsselstellung wird die Finanzierung über Gebühren und die Privilegierung bei Frequenzvergabe bzw. Kabelbelegung gerechtfertigt. Die Grundversorgung wird gesetzlich im „Programmauftrag“ konkretisiert, demzufolge das Programm der ÖRA politische Information, Bildung und Unterhaltung vermitteln soll. Für die politische Information sind öffentliches Interesse und Vielfalt der Meinungen maßgebende Richtwerte. Hinzu kommt insbesondere bei den Mehrländeranstalten eine Ausgewogenheit nach regionalem Aspekt. Im Hinblick auf Bildung und Unterhaltung werden von einem öffentlichrechtlichen Programm ein bestimmtes Niveau nach Maßstäben der Hochkultur und die Berücksichtigung von Minderheiten erwartet. Der Programmauftrag hat Konsequenzen für die Gestaltung des einzelnen Programms und für das öffentlich-rechtliche Programmangebot insgesamt.

Zwar hat das BVerfG in seinem sechsten Rundfunkurteil 1991 den öffentlichrechtlichen Rundfunk mit einer „Bestands- und Entwicklungsgarantie“ ausgestattet; dadurch wird ein Ende der Anstalten durch Konkurs oder durch politische Entscheidung praktisch ausgeschlossen. ${ }^{57}$

\footnotetext{
${ }^{56}$ Siehe dazu 5.2.3.

${ }^{57}$ BVerfGE 83, 238. Vgl. dazu Heinrich 1999: 87. Die Garantie bildete ursprünglich die Bedingung der SPD für die Zustimmung der SPD zur Einführung privaten Rundfunks (Langenbucher 1999: 234). Sie wurde dann später auch in den RStV aufgenommen.
} 
Aber die ÖRA müssen nachweisen, dass Ausweitungen ihres Angebotsspektrums (Ausbau der regionalen Dritten Fernsehprogramme zu nationalen Vollprogrammen, Spartenkanäle, digitale Programmbouquets) aus dem Auftrag zur Grundversorgung heraus zu rechtfertigen sind oder nicht. Für diesen Nachweis wurde die Grundversorgung zum „Funktionsauftrag“ ausgeweitet. Die Hürden für den Nachweis sind hoch: Die Landesrundfunkpolitiker stellen jede Expansion unter einen staatsvertraglichen Erlaubnisvorbehalt. Umgekehrt wurde den ÖRA eine Intensivierung der europäischen Kooperation im Programmbereich durch die Rundfunkpolitik verordnet (ARTE u.a.). Zu einer spezifischen Regulierung im Hinblick auf den Erwerb von Rechten ist es bislang nicht gekommen - folglich stehen die ÖRA hier nach wie vor im Wettbewerb mit den PKA.

Lange Jahre bot der Verzicht auf eine Erweiterung der Übertragungskapazitäten die Möglichkeit, durch beschränkte Programmauswahl die Konkurrenz um die Aufmerksamkeit der Rezipienten zu dämpfen und den politischen Botschaften gute Ausgangsbedingungen zu verschaffen. Auch bei mittlerweile erweiterten Kapazitäten sorgen Privilegierungen für öffentlich-rechtliche Fernsehprogramme für verbesserte Kommunikationschancen der politischen Akteure.

„Solange und soweit“ die Grundversorgung durch ÖRA gewährleistet werde, seien an die PKA nicht gleich hohe Anforderungen zu stellen - so das BVerfG. Aber sie sind nicht vollständig aus der publizistischen Verpflichtung entlassen; vor allem über den Hebel des Zulassungsverfahrens werden ihnen publizistische Leistungen abgerungen. In den Kriterien für die Auswahl zwischen konkurrierenden Bewerbern um eine Frequenz mischen sich publizistische und ökonomische Momente: ${ }^{58}$ Neben „wirtschaftlichem Engagement im Zulassungsgebiet“ sind die „Relevanz für Meinungsvielfalt“ und das „Ausmaß an tagesaktueller Berichterstattung“ entscheidende Kriterien. Dadurch wird ein Anteil politischer Information im Programm erreicht, der oberhalb dessen liegt, was Sender und Rezipienten freiwillig anbieten bzw. nachfragen. Da der Markt nur wenige private Angebote trägt, bleiben die publizistischen Anforderungen weiterhin hoch und werden nicht reduziert. Die Landesmediengesetze orientieren sich zwar grundsätzlich auf eine außenpluralistische Struktur, bei der die Vielfalt durch eine Vielzahl unabhängiger Rundfunkanbieter gewährleistet sein soll. Aber da in keiner Weise abzusehen ist, dass eine hinreichende Vielzahl von Programmen finanzierbar ist, wird weiterhin Binnenpluralismus gefordert sein, also eine Meinungsvielfalt innerhalb der Programme.

\footnotetext{
${ }^{58} \mathrm{Zu}$ den Regelungen zur Zulassung in den Landesmediengesetzen vgl. Herrmann 1994: 415.
} 
Auch die Unterscheidung von Voll-, Sparten- und Fensterprogrammen bietet Möglichkeiten des Eingriffs, z. B. durch die Auflage, im Rahmen von Vollprogrammen regionale Formate zu senden oder bei einem bestimmten Marktanteilen Fensterprogramme von Unabhängigen einzurichten. ${ }^{59}$

Nicht durchsetzbar war die vor allem von Frankreich favorisierte verbindliche Quotierung im Hinblick auf den Anteil nationaler bzw. europäischer Produktionen am TVProgramm - dies hätte die Abschottung der nationalen Fernsehmärkte gegen ausländische Anbieter ergänzt. Aus einer Vielzahl von Gründen blieb es bei einer SollVorschrift im Rundfunkstaatsvertrag, den Hauptteil des Programms Werken europäischen Ursprungs vorzubehalten.

Selbstverständlich gelten für öffentlich-rechtliche und private Anbieter gleichermaßen die allgemeinen publizistischen Regeln, mit denen Rechtsgüter geschützt werden sollen, die mit der Rundfunkfreiheit kollidieren. So wird im Hinblick auf den Schutz der Persönlichkeit von denjenigen, über die berichtet wird, auch im Rundfunk zwischen der Individual-, der Privat- und der Intimsphäre unterschieden. Beim Jugendschutz war es vor allem erforderlich, fernsehgerechte Auflagen zu formulieren. Verboten sind pornographische und gewaltverherrlichende Inhalte. Unterhalb dieser Verbotsschwelle wurden die Altersfreigaben für Kinofilme in Sendezeitbeschränkungen übersetzt. So können Filme, die ab 18 Jahren freigegeben sind, erst ab 23 Uhr gezeigt werden. Vor allem für die Einordnung von Filmen, die keine Alterseinstufung haben, haben die privaten Sender die „Freiwillige Selbstkontrolle Fernsehen“ gegründet, auch um geplanten Verschärfungen der Vorschriften zuvorzukommen. Auch in anderen Programmbereichen (z. B. Talkshows) ist es aus diesem Grund zu Selbstkontrollmaßnahmen gekommen. Dennoch wurde die Regulierung verschärft: So ist die Ausstrahlung von Filmen, die von der „Bundesprüfstelle für jugendgefährdende Schriften“ auf den Index gesetzt wurden, ist grundsätzlich verboten; die Rundfunkräte bzw. die LMA können aber Ausnahmen gestatten. Im digitalen Fernsehprogramm kann von der Sendezeitbeschränkung abgewichen werden, statt dessen erfolgt eine individuelle Freigabe der Sendungen. Mittlerweile stimmen sich die LMA intensiver als früher im Hinblick auf den Jugendschutz ab, z. B. durch gemeinsame Richtlinien. Der Jugendschutz reicht bis in den Werbebereich hinein: so ist Rundfunkwerbung für Tabakwaren und für Spirituosen nicht

${ }^{59}$ Demgegenüber von geringerer publizistischer Bedeutung ist die Verpflichtung, den Parteien während des Wahl- 
erlaubt, ebenso wenig das Sponsoring durch entsprechende Firmen. Unterbrecherwerbung bei Kindersendungen ist nicht zulässig.

Andere Regulierungen der Rundfunkwerbung werden mit dem Schutz der Rezipienten bzw. Verbraucher insgesamt begründet, z. B. die die Festlegung, ab welcher Länge welche Fernsehsendungen durch Werbung unterbrochen werden dürfen, und die Gebote, Werbung und Programm eindeutig zu trennen, gesponserte Sendungen zu kennzeichnen und die Spots in Blöcken zu bündeln. Im Gegenzug wurden neue Formen der Werbung (Teleshopping, Product Placement) zunächst toleriert, dann auch formell zugelassen.

Die Kontingentierung der Werbung und des Teleshoppings im Rundfunk hat hingegen vor allem strukturpolitische Motive und Effekte. Von den Begrenzungen der Werbung im privaten Rundfunk auf $20 \%$ der Sendezeit profitiert die Presse, insbesondere die Publikumszeitschriften; von denen beim öffentlich-rechtlichen Fernsehen (Begrenzung auf 20 Minuten werktäglich vor 20 Uhr bei ARD und ZDF) profitieren die Presse und die privaten Fernsehanbieter.

Zusammengefaßt: Mit Regulierung wird dafür gesorgt, dass bei Kommunikationsinhalten nicht alles zugelassen ist, was Aufmerksamkeit erregen könnte, sondern dabei auch Schutzrechte gewahrt werden - sowohl für Redaktions- als auch für Insertionsprogramme (Sorgfaltspflicht, Jugendschutz, vergleichende Werbung u. a. m.). Einschränkungen der Rundfunkwerbung sind protektionistische Maßnahmen für die Presse, sie dienen aber auch dazu, die Kommunikationschancen der politischen Organisationen in Presse und Rundfunk zu verbessern. Mit der Verpflichtung auf die Grundversorgung und mit anderen programmstrukturellen Vorschriften bleiben auch unter verstärkter Konkurrenz und bei veränderten Präferenzen der Rezipienten die Publizitätschancen für politische Organisationen gewahrt. 


\subsubsection{Wie? Regulierung der Prozeduren der Rundfunkkommunikation}

Nicht nur Teilnehmer und Inhalte, auch die Art und Weise der Rundfunkkommunikation unterliegt Regulierungen - sie geben verbindliche Antworten auf die Frage: Wie darf und wie darf nicht gesendet und empfangen werden?

So wird die Verfügung über Übertragungsrechte für große Sportereignisse durch rundfunkpolitische Entscheidungen auf europäischer Ebene eingeschränkt. Explizit wurde auf Grundlage einer Forderung des Europarats ein höchstrichterlich abgesichertes Recht auf Kurzberichterstattung von öffentlichen Ereignissen eingeführt, das einem Fernsehveranstalter von dem Inhaber der Übertragungsrechte für diese Ereignisse nicht streitig gemacht werden kann, für dessen Inanspruchnahmen aber ein „,billiges Entgelt“ (§ 5 Abs. 7 RStV) verlangt werden darf, um dessen konkrete Ausgestaltung es aber immer wieder Auseinandersetzungen gibt.

Umstrittener ist die Regelung, dass Ereignisse von nationaler Bedeutung, wie z. B. Fußballspiele der Nationalmannschaft, auch im frei empfangbaren Fernsehen gezeigt werden müssen, nicht ausschließlich im Pay-TV. Die novellierte Fernsehrichtlinie der EU erlaubt jedem Mitgliedsland, mit einer Auflistung von solchen Ereignissen die Nutzung der Übertragungsrechte einzuschränken, wobei die Listen divergieren können eine Reaktion auf die stark gestiegenen Programmpreise bei Sportübertragungen, die eine Auswertung über das Pay-TV zur Folge haben.

Ein weiteres Beispiel für die Regulierung der Prozeduren ist die Festlegung von Standards für Produktion, Übertragung und Empfang von analogem und nun auch von digitalem Rundfunk, die eine bestimmte Qualität der Kommunikation sichern sollen (Signal-Rausch-Abstand) und mit mehr oder weniger großem Erfolg im transnationalen Rahmen zustande kamen. Insbesondere der Standardisierung in der Kompression von Audio- und Videosignalen kommt eine bahnbrechende Bedeutung für die weitere Entwicklung der Rundfunklandschaft zu. Mit dem digitalen Fernsehen sind in verstärktem Maße Datenschutzprobleme verbunden, denen mittlerweile auch rundfunkrechtliche Regulierungen gelten. ${ }^{60}$

\footnotetext{
${ }^{60}$ Siehe dazu unten die weitgehend inhaltsgleichen Regelungen für Tele- und Mediendienste (5.3.4).
} 
Im Mittelpunkt der Regulierung des Modus der Rundfunkkommunikation stehen die Regelungen zur Finanzierung. ${ }^{61}$ Die Rundfunkpolitik garantiert den ÖRA ihre Finanzgrundlage dadurch, dass jeder Rundfunkteilnehmer unabhängig von der Nutzung öffentlich-rechtlicher Angebote zur Zahlung von Gebühren verpflichtet wird und dass die finanziell starken ÖRA die finanziell schwachen alimentieren. Der verbindliche Gebührensatz wird seit 1996 alle zwei Jahre in einem mehrstufigen Aushandlungsprozeß zwischen den ÖRA, einer Kommission aus Sachverständigen ${ }^{62}$ und den Landesregierungen bzw. den sie stützenden Parlamentsfraktionen erhöht. ${ }^{63}$ Den Rahmen dafür hat das BVerfG mit dem siebenten und achten Rundfunkurteil gesteckt, um einerseits Staatsferne zu gewährleisten, andererseits der Budgeterweiterung Schranken zu setzen. ${ }^{64}$ Auf diese Weise wird die Finanzierung des öffentlich-rechtlichen Rundfunks so abgesichert, dass kein Sender und kein Bundesland die Rezipienten aus der Gebührenpflicht entlassen kann, auch nicht in abgestufter Form.

Über das Verfahren der Gebührenfestsetzung haben die politischen Akteure die Möglichkeit, am Interesse der öffentlich-rechtlichen Anbieter an einer Maximierung des Budgets anzusetzen und deren Bereitschaft zur Lieferung von Publizität zu sichern. Die Gebührenfinanzierung ist seit 1997 auch auf EU-Ebene abgesichert (Protokoll zum Vertrag von Amsterdam); lange Zeit hatte die EG-Kommission darin lediglich eine Wettbewerbsverzerrung gesehen. Aus dem Gebührenaufkommen wird auch die Kontrolle des privaten Rundfunks, also die LMA finanziert. Nicht durchsetzen ließ sich die Einbeziehung von online-fähigen Computern in die Gebührenpflicht.

\subsubsection{Fazit: Ökonomisierung und Europäisierung der Rundfunkpolitik}

Nach wie vor wird die rundfunkpolitische Agenda von Fragen dominiert, die unter einem publizistischen Aspekt ein Problem darstellen: Meinungsvielfalt, Informationsleistung, Stellenwert politischer Themen. Aber mehr und mehr schieben sich ökonomische Probleme auf die vorderen Plätze der Agenda: grenzüberschreitende Freizügigkeit für Produkte, Dienstleistungen, Arbeit, Kapital auch im Rundfunkbereich, Wettbewerbsfähigkeit, Standortfaktoren. Es bleibt aber weiterhin eine explizit rundfunkpoliti-

\footnotetext{
${ }^{61}$ Einen Überblick bietet Karrass 1994.

${ }^{62}$ In die „Kommission zur Überprüfung und Ermittlung des Finanzbedarfs der Rundfunkanstalten“ (KEF) werden unabhängige Sachverständige, Vertreter der Rechnungshöfe und Vertreter der Staatskanzleien berufen (vgl. Heinrich 1999: 93).

${ }^{63}$ Vgl. RFGebStV und RFinStV.

${ }^{64}$ BVerfGE 87, 181; 90, 60 (1992 und 1994).
} 
sche Agenda. Mit dem digitalen Fernsehen rücken zusätzliche Fragen auf die rundfunkpolitische Agenda, die eine Brücke zur Onlinepolitik darstellen - insbesondere der Datenschutz.

Komplementär dazu verändert sich die Arena: Nach wie vor sind CDU/CSU und SPD, die Landesregierungen und die von ihnen beschickte Rundfunkkommission und schließlich die Landesmedienanstalten rundfunkpolitische Akteure von Gewicht. Sie setzen sich in mittlerweile routiniert eingespielten Verfahren der Konfliktaustragung und der Konsensfindung (,kooperativer Föderalismus“) miteinander und mit den Rundfunkanbietern auseinander - den ÖRA und den PKA, wobei die Verbandsebene bei beiden Gruppen von Anbietern im Vergleich zur Presse eher schwach ausgeprägt ist. ${ }^{65}$ Grundlage für alle bildet die Orientierung am BVerfG - einem Akteur mit dem Motiv und den Ressourcen, den Rundfunkbereich zu gestalten.

Gegenüber der nationalen und regionalen gewinnt die supranationale Ebene an Boden. Insbesondere die EU-Kommission wird mehr und mehr zu einem Gegengewicht gegenüber den föderalen Akteuren. Aber auch dadurch hat die Akteurskonstellation keine pyramidale Gestalt angenommen: Die hoheitlichen Instanzen - ob regional, national oder supranational - bilden einen Teil des rundfunkpolitischen Netzes und handeln mit den anderen Mitspielern - Unternehmen und Verbänden - tragfähige Lösungen für die anstehenden Probleme aus.

Insofern korrespondieren Ökonomisierung und Europäisierung der Rundfunkpolitik nationale publizistische Erfordernisse kollidieren mit den transnationalen ökonomischen Erfordernissen (vgl. Eifert/Hoffmann-Riem 1999: 91).

\subsection{Onlinepolitik in Deutschland: Regulierung im Schnittpunkt unter- schiedlicher Politiktraditionen}

Die Konvergenz von Rundfunk, Telekommunikation und Informatik hat nicht nur unter technischem und ökonomischem Aspekt, sondern auch unter politisch-rechtlichem As-

\footnotetext{
${ }^{65}$ Man kann die ARD als die (schwach ausgeprägte) Verbandsebene der ÖRA kennzeichnen. Parallel zum Wandel der Arena verändert sich das Leitbild des Rundfunkanbieters: Es war über lange Zeit geprägt von öffentlichrechtlichen Anstalten, die ohne Gewinnorientierung arbeiten; imageprägend wurden dann Gesellschaften, die von Verlagshäusern mit publizistischem Profil geführt wurden. Nunmehr beherrschen Unternehmen das Bild, die Medien nicht mehr publizistisch, sondern ökonomisch betrachten, deren Aktivitäten sich über die ganze Medienpalette und über die gesamte Verwertungskette erstrecken und die nicht national, sondern transnational agieren.
} 
pekt neue Schnittmengen hervorgebracht. Onlinepolitik ${ }^{66}$ steht im Schnittpunkt von drei sehr unterschiedlichen Politikkulturen:

- Die Informatikpolitik ist gekennzeichnet durch eine eher schwache Regulierung mit Datenschutz, Standardisierung und Technologieförderung als den zentralen Problemen.

- Die Telekommunikationspolitik hat erst vor kurzem mit einer Tradition der starken Regulierung von Teilnahme und Prozeduren der technisch vermittelten Individualkommunikation gebrochen. ${ }^{67}$

- Die Rundfunkpolitik zeichnet sich durch intensive Regulierung von Teilnahme, Inhalt und Prozedur der medialen öffentlichen Kommunikation aus.

\subsubsection{Regulierung durch wen? Massen- oder Individualkommunikation?}

Eine besondere politische Herausforderung liegt darin, dass diese Bereiche in unterschiedliche Kompetenzbereiche fallen: Rundfunk ist Ländersache, Telekommunikation und Informatik sind Bundessache. Damit war zunächst offen, wer den Bereich der Online-Kommunikation - nicht ihre technische Infrastruktur - zu regulieren habe. Das digitale Fernsehen mit seiner Möglichkeit der Verbindung von Sender und individuellem Rezipient wurde dem Rundfunk zugeschlagen. Schwieriger war es bei den Onlinediensten, die über das WWW öffentlich angeboten und genutzt wurden. Dabei handelt es sich offensichtlich weder um klassische Massenkommunikation noch um klassische Tele-Individualkommunkation. Da weder Bund noch Länder den Bereich aus ihrer Kompetenz entlassen wollten, hat man den Bereich in „Teledienste“ und „Mediendienste“ aufgeteilt, wobei für erstere der Bund, für letztere die Länder zuständig zeichneten. Je mehr Eigenschaften ein Online-Angebot mit dem klassischen Rundfunk gemeinsam hat, desto größere publizistische Relevanz wird ihm unterstellt, desto enger sind die Regulierungen - und desto eher fällt er als Mediendienst unter Länderkompetenz, ist aber damit noch nicht „Rundfunk“. Je mehr Eigenschaften er mit der klassischen Tele-Individualkommunikation gemeinsam hat, desto eher ist es ein Teledienst und fällt in Bundeskompetenz. Ein Dienst, etwa ein Wetterinformationsdienst oder ein Einkaufsportal für die Autoindustrie, wird nach folgenden implizit in den Gesetzen enthaltenen Kriterien geprüft:

\footnotetext{
66 „Onlinepolitik“ wird hier den anderen möglichen Bezeichnungen wie „Telematikpolitik“, „Mediamatikpolitik“ (Latzer 1997), „Multimediapolitik“ (Hoffmann-Riem) oder „Netzpolitik“ vorgezogen. Vgl. zum folgenden Schulz 1997.

${ }^{67}$ Vgl. Schneider 1999.
} 
- Grad an Publizität: Angebot für eine Allgemeinheit oder individuumsspezifisches Angebot?

- Grad an Interaktivität: Verteilmodus oder Dialogmodus?

- Grad an Multimedialität: Audiovisuelles Angebot oder Textangebot?

Die Mediendienste sind im Mediendienstestaatsvertrag (MdStV) und die Teledienste im Informations- und Kommunikationsdienstegesetz (IuKDG) geregelt. Vieles ist in beiden Gesetzeswerken inhaltsgleich geregelt; bei den Mediendiensten wird aufgrund ihrer größeren Nähe zum Rundfunk mehr geregelt als bei den Telediensten. Damit war der Online-Bereich aus der dichten Rundfunkregulierung herausmanövriert, aber die Länder blieben trotzdem in der Arena.

\subsubsection{Wer? Regulierung der Teilnahme an der Onlinekommunikation}

Im Unterschied zu Presse und Rundfunk sind in der Onlinekommunikation die kommunikativen Rollen weniger starr festgelegt als in anderen Medien. Wer als Individuum oder als Organisation Onlinemedien nutzt, tut dies in relativ höherem Maße nicht nur rezeptiv, sondern auch durch eigene kommunikative Angebote, z. B. in Form selbst verantworteter Homepages oder durch Beteiligung an Mailinglists und News-Groups.

Der Zugang zum Online-Bereich - zu welcher kommunikativen Rolle auch immer - ist von Beginn an weitgehend liberal gehandhabt worden. Jeder kann Dienste oder Infrastrukturleistungen entwickeln und anbieten, ohne ein Zulassungsverfahren durchlaufen oder sich einer eigenständigen Konzentrationskontrolle unterwerfen zu müssen. Die LMA prüfen, ob ein Dienst als Mediendienst oder als Rundfunk einzuordnen ist; im letzteren Falle unterliegt er einem Zulassungsverfahren. Ebensowenig wird der Zugang durch einen Universaldienst analog zum Telekommunikationsgesetz gesichert, etwa durch ein flächendeckendes Angebot von öffentlich finanzierten Zugangsterminals.

Die Teilnahme ist folglich weder in positiver und noch in negativer Hinsicht reguliert; gewährleistet wird der offene Zugang, nicht aber ein allgemeiner Zugang.

\subsubsection{Was? Regulierung der Inhalte der Onlinekommunikation}

Mitte der 90er Jahre trat das WWW in die öffentliche Wahrnehmung und entwickelte sich mit einer bislang medienhistorisch nicht gekannten Geschwindigkeit zu einem 
Massenmedium. Vergleichsweise verhalten gestaltete sich die öffentliche Kommunikation über Chancen und Risiken des neuen Mediums. Öffentliche Aufmerksamkeit bei den Inhalten errangen vor allem Kinderpornographie und NS-Propaganda - verbunden mit der Verunsicherung, ob Straftatbestände tatsächlich verfolgt werden könnten. Die öffentliche Diskussion bildet den Hintergrund für die Regulierung in Gestalt der beiden Regelwerke: Bei potentiellen Investoren und professionellen Anbietern war angesichts der öffentlichen Diskussion unklar, welche Eingriffe der Bereich zu erwarten habe, wie sich Gerichte und Behörden in verschiedenen Bundesländern gegenüber den Angeboten und Dienstleistungen verhalten würden. Die Tatsache, dass es nun einen festgelegten einheitlichen Rahmen von Mindeststandards gibt, wirkte bereits stabilisierend auf Behörden, Anbieter und Nutzer, und damit als günstige Rahmenbedingung für die weitere Entwicklung. Einmal getroffene verbindliche Regelungen bringen Stabilität - da Überraschungen durch einzelne Bundesländer und durch öffentlichen Druck ausgeschlossen werden. Mit der Regulierung in Gestalt der beiden Regelwerke war die Onlinekommunikation dem engen Korsett der Rundfunkregulierung entschlüpft. Die Regulierung ermöglichte durch flankierende stabilisierende Schutzvorkehrungen eine dynamische Entwicklung des Bereichs. (vgl. Schulz 1997)

Die letztlich beschlossenen inhaltlichen Regeln für Online-Angebote orientierten sich mehr an der Presse als am Rundfunk; den Angeboten wurde nicht die gleiche Wirkungsmacht unterstellt wie einem Rundfunkprogramm. Die politisch wichtigste Frage lautete: Wer verantwortet was? An wen kann man sich im Falle strafbarer Texte oder Bilder halten? Auf Grundlage einer Unterscheidung von logisch getrennten Anbietertypen wurden unterschiedliche Verantwortungsgrade definiert:

- Ein Content provider bietet eigene Inhalte an und wird bei Verstößen gegen die Vorschriften strafrechtlich oder zivilrechtlich zur Rechenschaft gezogen.

- Ein Service provider bietet fremde Inhalte an und kann dann für strafbare Inhalte zur Verantwortung gezogen werden, wenn er davon Kenntnis hatte, die fraglichen Inhalte also vorsätzlich anbietet oder es unterlassen hat, sich einen regelmäßigen Überblick über ein Angebot zu verschaffen, und wenn die Sperrung der Nutzung technisch möglich und ökonomisch zumutbar gewesen wäre.

- Ein Access provider ermöglicht lediglich den Zugang zum Internet. Man hat sich darauf verständigt, sie nicht anders zu behandeln als Telefongesellschaften. Wer In- 
halte aus technischen Gründen allenfalls zwischenspeichert, der wird nicht für Inhalte verantwortlich gemacht.

Besondere Bedeutung wird in der öffentlichen Diskussion dem Jugendschutz zugemessen. Nach dem MDStV sind Angebote, die das Wohl von Kindern und Jugendlichen beeinträchtigen, nur mit besonderen Vorkehrungen zulässig, die unwahrscheinlich machen, dass Kinder und Jugendliche erreicht werden. Bei Verteildiensten dürfen solche Angebote nur für die Zeit ins Netz gestellt werden, zu denen „üblicherweise“ Jugendliche nicht mehr erreicht werden (analog zum Rundfunkstaatsvertrag). Abrufdienste mit derartigen Inhalten dürfen nur angeboten werden, wenn sie technische Sperrvorkehrungen beinhalten. Außerdem werden die Anbieter analog zum Rundfunkbereich verpflichtet, einen Jugendschutzbeauftragten zu bestellen. Als Alternative dafür können die Anbieter einer Organisation zur Selbstkontrolle der Anbieter beitreten. Diese Regeln gelten selbstverständlich nur für inländische Anbieter - in der dargelegten Differenzierung von Verantwortlichkeit. Bislang ist nicht ersichtlich, dass es zu grenzüberschreitenden Jugendschutzkonventionen kommen wird.

Außerdem gelten die generellen Grundregeln für journalistisches Handeln auch für Online-Angebote mit publizistischen Zielen: Impressumspflicht, Sorgfaltspflicht, Gegendarstellungsrecht, Trennungsgebote zwischen Nachricht und Kommentar bzw. zwischen Werbung und redaktionellem Angebot.

Im Hinblick auf Navigationshilfen (z. B. Suchmaschinen) ist erst jüngst Regulierungsbedarf thematisiert worden - mit dem Verweis auf deren wachsende Bedeutung für die Informationssuche und Selektion (Schulz/Held/Kops 2001).

\subsubsection{Wie? Regulierung der Prozeduren der Onlinekommunikation}

Die technische Infrastruktur der Onlinekommunikation wird durch massive staatliche Förderung - z. B. in Pilotprojekten mit gemischter Finanzierung - aufgebaut wird verbunden mit einer deutlichen De-Regulierung. Bis zur mehrstufigen Postreform war hoheitlich reglementiert, mit welchen Leistungsmerkmalen die kommunikationstechnische Infrastruktur auszustatten war - auch zum Schutz nationaler Produzenten. Dies wird nun - dem Muster der Informatik folgend - stärker dem Markt überlassen. Dadurch gewinnen die Interessen von Anwendern an Gewicht. Der Spielraum wird nun 
zunehmend durch Standardisierungsgremien auf internationaler Ebene eingegrenzt, in denen die Unternehmen und Verbände eine tragende Rolle spielen. Hier bilden sich neue Foren heraus, in denen veränderte Problemlagen mit neuen Aushandelungsformen angegangen werden. Ein herausragendes Beispiel ist die Organisation der Vergabe von Adressen im Internet (IP-Nummernbereiche und Domain-Namen) durch die expertendominierte

ICANN. ${ }^{68}$

Mit einem Teil des IuKDG, dem Gesetz über die digitale Signatur, wird eine Sicherheitsinfrastruktur für die elektronische Kommunikation aufgebaut. Mit der digitalen Signatur kann geprüft werden, ob eine elektronische Sendung tatsächlich von demjenigen stammt, der als Absender deklariert ist, und ob die Sendung unversehrt ist oder während der Übermittlung verändert wurde. Von daher ist die Signatur als Unterschrift und als Siegel zu verstehen. Die Versiegelung geschieht mit einem privaten Schlüssel, die Prüfung mit öffentlichen Schlüsseln, deren Zuordnung zu der Person mit dem privaten Schlüssel von Zertifizierungsstellen bescheinigt wird. Die Zertifizierungsstellen sind Organisationen mit einer Lizenz der Regulierungsbehörde für Telekommunikation. Damit wurde nicht der Versuch verbunden, andere Verschlüsselungssysteme zu verbieten; ebensowenig wurden damit Möglichkeiten für ein Eindringen des Staates in die Onlinekommunikation reserviert, z. B. durch eine Pflicht, die Schlüssel bei einer Behörde zu hinterlegen. Dies steht in der Tradition der Telekommunikation, bei der das Fernmeldegeheimnis dafür sorgt, dass nur unter sehr restriktiven Bedingungen der Staat Kenntnis vom Inhalt nehmen darf und dass dies privaten Interessenten generell untersagt ist.

Unverschlüsselte Kommunikation im Netz hinterläßt Spuren, aus denen sich Nutzungspfade und damit auch Persönlichkeitsprofile rekonstruieren lassen. Auf der Grundlage des Grundrechts auf „informationelle Selbstbestimmung“ (BVerfGE 65, 1) sehen die Gesetze u.a. folgende Datenschutzvorschriften vor:

- Weitestgehende Vermeidung und frühestmögliche Löschung von personenbezogenen Daten als Verpflichtung für die Anbieter;

\footnotetext{
${ }^{68}$ The Internet Corporation for Assigned Names and Numbers.
} 
- Erhebung von Daten für die Nutzung und Abrechnung nur bei widerrufbarer Einwilligung des Nutzers und Ermöglichung der anonymen oder pseudonymen Benutzung;

- Möglichkeit der Auskunft über die gespeicherten Daten;

- Verbot der Weitergabe und Zusammenführung von nicht-anonymisierten Daten.

Auch in diesem Bereich sorgt die EU mit einer Richtlinie für eine Transnationalisierung der Regulierung. Weitere Regulierungen, insbesondere der mit Bestellung verbundenen Kommunikation, sind zu erwarten.

\subsubsection{Fazit: Rasante Entwicklung - stabilisiert durch Regulierung außerhalb des Rundfunks}

Die Agenda der Onlinepolitik ist geprägt von einer ambivalenten öffentlichen Diskussion, in der einerseits Inhalte thematisiert werden, denen negative Wirkung unterstellt wird, und in der andererseits günstige Bedingungen für die dynamische Entwicklung eines Kommunikationsbereichs gefordert werden, dem wie kein anderer Modernität und Prosperität zugesprochen wird. Dafür ist ein zurückhaltender rechtlicher Rahmen geschaffen worden. Weniger öffentlich thematisiert, aber langfristig von größerer Bedeutung ist, dass durch den Einfluß der Informatiktradition neue Probleme in die Medienpolitik gekommen sind, vor allem die Datensicherheit und der Datenschutz.

Die Arena der Onlinepolitik ist geprägt von dem Kompetenzstreit zwischen Bund und Ländern. Ihr Verhältnis geriet durch den Regelungsbedarf im Online-Bereich aus der traditionellen Balance. Sie wurde durch die Teilung des Bereiches wieder hergestellt; damit war verhindert, dass die Länder aus der Arena gedrängt wurden. Da die publizistische Bedeutung dieses Medienbereiches als relativ schwach angesehen wird, haben sich die Parteien nur schwach in diesem Bereich engagiert. Die Organisation der wirtschaftlichen Interessen gestaltet sich unübersichtlicher als in anderen medienpolitischen Konstellationen: Es sind neue Verbände gegründet worden (z. B. der Deutsche Multimedia-Verband), und die Unternehmen selbst sowie informelle Nutzervereinigungen sind in die Vorbereitung und Begleitung der Regulierung involviert. Dabei versuchen die Akteure, die Probleme aus der hoheitlichen Regulierung herauszuhalten und in Form von Selbstregulation zu lösen. In vergleichsweise hohem Maße sind transnationale Akteure in die Regulierung eingebunden. ${ }^{69}$

${ }^{69}$ Mueller 2000; Zerdick, Picot, Schrape et al. 1999. 
Insgesamt haben sich Agenda und Arena binnen kürzester Frist gebildet. Auch die Politik erreicht im Tempo der Regulierung die Beschleunigung, der die Medienentwicklung in Gestalt der Online-Kommunikation unterliegt. Im Gegenzug gibt die Regulierung der dynamischen Entwicklung ein stabiles Gerüst. 


\section{Differenzierung von Entscheidungsebenen: Regulierung, Ordnung, Orientierung}

Noch eine dritte Differenzierung ist erforderlich: So wie die Regulierungen den Spielraum der kommunikativen Akteure begrenzen, so ist auch der Spielraum der regulierenden Akteure begrenzt - durch Regeln für die Entscheidung. Die sind zunächst einmal im politisch-rechtlichen Ordnungsrahmen festgelegt, der seinerseits wieder in grundlegenden Orientierungsmustern wurzelt. Diese beiden Ebenen oberhalb der Regulierung gilt es noch in das Gesamtbild der Medienpolitik einzubeziehen.

\subsection{Der politisch-rechtliche Ordnungsrahmen: Restriktion der medienpolitischen Interaktion}

Die medienpolitische Ordnung umfaßt insbesondere die in der Verfassung garantierten Grundfreiheiten, die Kompetenzverteilungen und Verfahrensregeln. Die Regulierungsentscheidungen werden durch diesen Ordnungsrahmen ermöglicht und begrenzt, aber nicht determiniert - so wie auch die öffentliche Kommunikation nicht durch deren Regulierung determiniert wird.

\subsubsection{Kommunikationsfreiheiten: Grenzziehung zwischen Medien und Staat}

Das zentrale Element des Ordnungsrahmens bilden die Kommunikationsfreiheiten die Meinungsfreiheit, die Informationsfreiheit und die Medienfreiheit. In der deutschen verfassungsrechtlichen Diskussion wird die Medienfreiheit in unterschiedlicher Weise auf die Regulierung bezogen: Aus einem traditionell liberalen Verständnis heraus wird die Medienfreiheit als Freiheit vom Staat, als Garantie einer Abwehr staatlicher Eingriffe und der Autonomie des Medienbereiches gesehen. Folgt man dieser Auffassung, dann darf in die Kommunikationsbeziehungen nur eingegriffen werden, so weit andere Grundrechte oder andere Rechte von Verfassungsrang geschützt werden - etwa der ausdrücklich im Artikel - genannte Jugendschutz als Ausdruck des Grundrechts auf freie Entfaltung der Persönlichkeit.

Gegenüber dieser negativen, auf Abwehr von Staatseingriffen gerichteten Auffassung der Medienfreiheit, hat sich eine positive Variante etabliert: Um der Medienfreiheit willen sei der Staat gehalten, die Medien zu regulieren, ihnen eine Ordnung zu geben. Die Medienfreiheit soll demzufolge nicht nur vor dem Staat, sondern durch den Staat geschützt werden. Um die Funktion der Medien für die Bildung öffentlicher Meinung 
zu sichern - der Begründungskern für die Medienfreiheit -, soll die Autonomie der Medien gegen Instrumentalisierungen durch einzelne politische Gruppen geschützt werden; aber auch gegen Unterhöhlung des publizistischen Auftrages durch Interessen außerhalb der Politik, etwa von Unterhaltungsbedürfnissen des Publikums oder von Anforderungen der Werbewirtschaft.

In diesem Spannungsverhältnis zwischen einer Freiheit der Medien vom Staat und einer Freiheit der Medien durch den Staat sind Zielkonflikte angelegt, von denen die medienpolitische Diskussion stark geprägt ist. ${ }^{70}$ Je nachdem, welche Seite in diesem Spannungsverhältnis dominiert, werden unterschiedliche Grenzen für die Regulierung gesteckt, und so hat die Dominanz der Interpretation der Medienfreiheit als Freiheit der Medien durch den Staat die medienpolitische Regulierung geprägt.

Ergänzt wird dies durch das Spannungsverhältnis im Hinblick auf die grundlegenden wirtschaftlichen Freiheiten. Die Gewerbe-, Eigentums-, Vertrags- und Koalitionsfreiheit als Gebote für Zurückhaltung des Staates werden konditioniert durch das Sozialstaatsgebot, mit dem Eingriffe auch in medienrelevante Eigentumsrechte und Arbeitsbeziehungen begründet werden können - auch diese Spannung von Gebot und Verbot staatlichen Handelns ermöglicht und begrenzt medienpolitische Regulierung.

\subsubsection{Kompetenzverteilung: Abgrenzung der Domänen}

Zentral für die Verteilung medienpolitischer Entscheidungsbefugnisse ist das Spannungsverhältnis zwischen Bund und Ländern. ${ }^{71}$ Immer wieder hat der Bund in allen hier behandelten Medienbereichen versucht, medienpolitische Kompetenzen an sich zu ziehen: durch Gründung einer zentralen Alternative zu den Landesrundfunkanstalten, durch ein Presserechtsrahmengesetz, durch ein Multimediagesetz u. a. m. Dies ist mit Hilfe des BVerfG von den Ländern weitgehend erfolgreich vereitelt worden. Um ihre Domäne verteidigen zu können, mußten sie allerdings unter Beweis stellen, dass sie zu einer kooperativen Politik mit dem Ergebnis bundeseinheitlicher Lösungen in der Lage waren - durch weitgehend identische Landespressegesetze, durch Kooperation in der Rundfunkkommission, durch eine gemeinsame Rechtsgrundlage für den Rundfunk- und

\footnotetext{
${ }^{70}$ Eifert/Hoffmann-Riem 1999: 73 sprechen von einem ,grundsätzlichen Dilemma einer verfassungsrechtlich gebotenen ... staatlichen Regelung bei gleichzeitigem verfassungsrechtlichem Verbot des staatlichen Einflusses auf die Inhalte.“ Jarren/Schulz 1999: 118 nennen dies eine ,scheinbar paradoxe Vorgabe.“

${ }^{71}$ Die staatsrechtlichen Details und die wechselvolle Entwicklung des Verhältnisses können hier nicht dargelegt werden.
} 
für den Onlinebereich (Rundfunk- bzw. Mediendienstestaatsvertrag) ${ }^{72}$, durch Kooperation der LMA über Partei- und Landesgrenzen hinweg u. a.m. Alle Versuche, ,unitarische Lösungen“ mit zentralen Regulierungseinrichtungen zu schaffen, sind am Widerstand der Länder gescheitert, um nicht den Bund damit zu stärken. Die Sorge davor hat ausgereicht, um auch bei großen Divergenzen zwischen den Parteien (Beispiel Zulassung privater Anbieter beim Kabelfernsehen) zu gemeinsamen Lösungen der Länder zu kommen (Beispiel Kabelpilotprojekte).

Anders ist es, wenn die Verbände und Unternehmen Kompetenzen reklamieren - wie es sich in den Selbstkontrolleinrichtungen für die Presse, die Werbung, die privaten Fernsehanbieter und den Multimediabereich ausdrückt. Dann waren die Länder eher bereit, Kompetenzen abzugeben.

Die partielle Verlagerung von Kompetenzen auf die supranationale Ebene der EU konnte durch die Länder nicht verhindert, nur verschoben werden. Es zeichnet sich für den Rundfunkbereich eine europäische Ordnung ab, deren kompetenzrechtliche Dimension durch die EG-Richtlinie „Fernsehen ohne Grenzen“ (1989/1997) deutlich markiert wurde: Eine Richtlinie ist im Hinblick auf das dort niedergelegte Ziel für alle EUStaaten verbindlich, es wird aber den einzelnen Staaten überlassen, wie die Ziele erreicht werden. Lange umstritten war, in welchem Maße die EU eine Kompetenz für Rundfunkfragen besitzt. Traditionell wurde der EU soweit Kompetenz für den Rundfunk zugestanden, wie im Hinblick auf die Dienstleistung Rundfunk Regulierungsbedarf (z. B. Werbekontingentierung) gesehen wird, also für die wirtschaftliche Tätigkeit. So weit in kultureller Hinsicht Regelungsbedarf gesehen wurde (z. B. Quotierung der Inhalte nach Ursprungsländern), falle der Rundfunk unter die Zuständigkeit nationaler Instanzen. Seit dem Vertragsschluß von Maastricht hat sich sich der Kompetenzbereich der EU über das wirtschaftliche Moment hinaus in die kulturellen Momente des Rundfunks hinein erweitert - getrieben von den besonderen Anreizstrukturen der EUKommission. Mit der Verpflichtung der EU auf das Subsidiaritätsprinzip ist aber Gewähr dafür gegeben, dass nicht alle Kompetenzen auf die supranationale Ebene gehoben werden. $^{73}$

\footnotetext{
${ }_{72}$ Eine Auflistung aller gemeinsamen Rundfunkstaatsverträge findet sich bei Stuiber 1998: 330f.

${ }^{73}$ Vgl. Heinrich 1999: 107ff; Dörr 2000.
} 
Ein Gegengewicht zu den Landesregierungen als medienpolitischen Akteuren bildet in vertikaler und horizontaler Hinsicht die Judikative. Insbesondere das Bundesverfassungsgericht setzt nicht nur für den Rundfunkbereich grundlegende Regeln und fällt dabei auch Entscheidungen über Kompetenzverteilungen. In keinem anderen Politikbereich ist dem BVerfG eine vergleichbare Gestaltungskraft zugestanden worden wie im Medienbereich (vgl. Ronneberger 1989). Das BVerfG hat in seiner Interpretation der Rundfunkfreiheit den Pol „Medienfreiheit durch den Staat“ gestärkt und damit seine eigene gestaltende Rolle begründet; denn auf dieser Grundlage kann die Rundfunkgesetzgebung daraufhin geprüft werden, ob sie der publizistischen Funktionszuweisung dient. ${ }^{74}$ Mit seinen Urteilen hat das BVerfG sich ja nicht darauf beschränkt, Gesetze auf ihre Vereinbarkeit mit der Verfassung zu prüfen, sondern der weiteren Gesetzgebung einen z. T. detaillierten Rahmen vorgegeben (Exemplarische Stichworte sind Grundversorgung und die Form der Aufsicht über den privaten Rundfunk). Hinter diesem Zugeständnis an das Gericht steht „offenbar die Vorstellung, dass die ,unabhängigen“ Verfassungsväter gleichsam wie ,wohlwollende Diktatoren“ politische gerechter zu entscheiden vermögen als Parlamente oder Regierungen.“ (Frey/Kirchgäßner 1994: 55).

Die kompetenzrechtlich abgesicherte Dominanz der Länder bzw. der Ministerpräsidenten, bei denen Medienpolitik zumeist ressortiert, hat den bereits erwähnten parteipolitischen Hintergrund: Je mehr von den Parteiführungen angenommen wird, dass die jeweils konkurrierende Partei die Regulierungskompetenz für den Medienbereich dazu benutzen konnte, um ihre publizistische Ausgangsposition zu verbessern, desto stabiler ist eine Kompetenzverteilung, wo nur im Konsens über Regulierungen des Medienbereichs entschieden werden kann. Durch die Länderkompetenz beim Rundfunk ist gewährleistet, dass beide großen Parteien beteiligt werden. Oder man akzeptiert, dass die Regulierungskompetenz auf eine Ebene geschoben wird, auf die beide Parteien einen gleich guten oder gleich schlechten Einfluß haben - wie das Bundesverfassungsgericht oder die EU.

\footnotetext{
${ }^{74}$ Hier muß ich eine handlungstheoretische Erklärung der Entscheidungen auf der Ordnungsebene schuldig bleiben. Erforderlich wäre in diesem Zusammenhang eine Anreizanalyse des BVerfG unter dem Stichwort ,Anerkennungsmaximierung“ (Bizer 2000: 78f). Vgl. auch die Arbeiten zur „,constitutional political economy“ (Rowley 1993a-c).
} 


\subsubsection{Verfahrensregeln}

Neben dem Ob und dem Wer der Regulierung bilden Festlegungen des Wie der Regulierung einen weiteren Teil des Rahmens: Das Verfahren der Regulierung wird insbesondere durch Regeln der prozeduralen Fairness strukturiert. Darunter fallen die Rechtsförmigkeit der Regulierung, die Festlegung eines Fahrplans mit unterschiedlichen Möglichkeiten der Einflußnahme auf den einzelnen Stufen, die Begründungspflicht für Entscheidungen, die Begrenzung der Revidierbarkeit, die Reduktion von Komplexität bei gleichzeitiger Bewahrung von Kontingenz durch Ausweisung von Mehrheits- und Minderheitspositionen - alles dies sind Stück für Stück erworbene Verfahrensregeln, die den Regulierungen ein prozedurales Gerüst und damit Legitimität geben.

\subsubsection{Fazit: Stabilität durch sachliche, soziale und zeitliche Strukturierung}

Regulierungen stehen folglich in einem Rahmen, über dessen Elemente selbst auch wieder in einer zumeist langwierigen Auseinandersetzung entschieden worden ist. Aber nach einer Festlegung ist der Rahmen der unmittelbaren Disposition der Akteure entzogen, so dass er der Interaktion der medienpolitischen Akteure ein stabilisierendes Gerüst geben kann.

Die Trennung der Ebenen - Entscheidungen erster und zweiter Ordnung - ist politisch von Belang, denn Konsens und Dissens können entsprechend divergieren: Medienpolitische Stabilität ist so lange gewährleistet, wie die Akteure sich auch bei harten Konflikten über eine spezifische Regulierung im Grundsatz darüber einig sind, ob und durch wen die strittige Angelegenheit zu entscheiden sei. ${ }^{75}$ Mit jeder Regulierung wird dieser Ordnungsrahmen aktualisiert, d. h. zugleich im Grundsatz bestätigt und in Nuancen verändert.

\subsection{Politisch-kulturelle Orientierungsmuster: der Horizont der Medienpolitik}

Der Ordnungsrahmen ist seinerseits geprägt von grundlegenden politisch-kulturellen Orientierungen - konventionalisierten Mustern, die Medienpolitik prägen, selbst aber den Entscheidungen weitgehend entzogen sind. 


\subsubsection{Wertehorizont: Freiheit, Gleichheit, Sicherheit}

Orientierung stiftet vor allem der Wertehorizont, die letztlich maßgebende Instanz für Regulierungs- und Ordnungsentscheidungen.

Die Entscheidungen über Regeln für öffentliche Kommunikation können sich letztlich orientieren an der

- Sicherheit des Gemeinwesens: dann soll vor allem verhindert werden, dass durch öffentliche Kommunikation Herrschaftsstrukturen oder Grundwerte gefährdet werden;

- individuellen Freiheit: dann soll vor allem gewährleistet werden, dass eine möglichst große Vielfalt kommunikativer Möglichkeiten zur Auswahl steht;

- Gleichheit der Gesellschaftsmitglieder: dann soll vor allem eine möglichst gleiche Teilhabe aller Gesellschaftsmitglieder an der öffentlichen Kommunikation erreicht werden.

Das Profil der jeweiligen nationalen (oder transnationalen) Medienpolitik ist bestimmt durch spezifische Mischungen dieser Leitwerte. ${ }^{76}$

\subsubsection{Kommunikationsbild: Starke Medien und schwache Massen}

Eine weitere tragende Säule des Orientierungsmusters bildet das dominante Medienbild, insbesondere die damit verbundenen Kausalschemata. Voraussetzung für alle medienpolitischen Entscheidungen ist die Unterstellung starker, direkter, genereller Wirkung von Medien - die es zu erzeugen, zu verhindern, zu gestalten, zu verzögern oder zu beschleunigen gilt. Hier sind die Unterschiede zwischen den Medien ein Indiz: Dem Fernsehen wird unvergleichlich größere Wirkung zugeschrieben als anderen Medien; folglich wird an der Idee der „Rundfunkordnung“ festgehalten, das bedeutet an der Gewährleistung der Rundfunkfreiheit durch den Staat - in deutlichen Kontrast zur Presseund Filmfreiheit. Wie so manches in der Medienpolitik ist auch dies zu einem guten Teil auf das BVerfG zurückzuführen, das nicht nur die Ordnung geprägt, sondern auch die kulturelle Orientierung artikuliert hat. ${ }^{77}$ Im Mittelpunkt der Vorstellungen steht dabei noch die publizistische Wirkung - dass den Medien ein hoher Stellenwert für die

\footnotetext{
${ }^{75}$ Diese Unterscheidung ist anders gelagert als die von kommunikationspolitischer Strategie und Taktik bei Rühl 1973: 17.

${ }^{76}$ Witte 1982; Vowe 1999.

${ }^{77}$ Klassisch die Formulierung des Gerichts „Unter den Medien kommt dem Rundfunk wegen seiner Breitenwirkung, Aktualität und Suggestivkraft besondere Bedeutung zu.“ (BVerfGE 1994, 36). Die Folgen reichen weit: „Nicht nur Demokratietheorie und Verfassungsrechtslehre, sondern auch sozialwissenschaftliche Analysen blieben von der Karlsruher Semantik verblüffend abhängig.“ (Langenbucher 1999: 230).
} 
öffentliche Meinung zugerechnet wird. Mehr und mehr tritt die ökonomische Wirkung in den Gesichtskreis - mediale Kommunikation als Indikator für soziale Modernität und wirtschaftliche Prosperität.

Die Attributionen (Ursachenzuschreibungen) werden in der öffentlichen Diskussion um so deutlicher akzentuiert, je relevanter die gesellschaftlichen Veränderungen eingeschätzt werden, die in einen Kausalzusammenhang mit Medien gestellt werden. Dabei werden entweder öffentlich wahrgenommene gesellschaftliche Veränderungen, wie z. B. ein Anstieg der Gewaltbereitschaft, auf Medieneinflüsse zurückgeführt. ${ }^{78}$ In der Konsequenz wird erwartet, dass die Medien politik dem Einhalt gebietet. Oder es werden in Folge von Veränderungen im Mediensystem bestimmte Wirkungen erwartet. ${ }^{79}$ Die sollen dann medienpolitisch gestaltet werden. Risiken - erwartete negativ bewertete Effekte - sollen ausgeschlossen, ihre Wahrscheinlichkeit zumindest gesenkt werden; Chancen - erwartete positiv bewertete Effekte - sollen genutzt, ihre Wahrscheinlichkeit zumindest erhöht werden. Wenn sich durch technologische und ökonomische Veränderungen das Mediensystem spürbar und grundlegend verändert, dann wird diese prognostische Wirkungsvermutung besonders akut.

Ergänzt wird das Bild der starken Medien durch die Vorstellung vom schwachen Publikum - eine formbare Masse, die es zu schützen, zu erziehen und zu lenken gilt.

Dieses Kausalmuster ist kontingent; grundsätzlich wäre auch ein anderes Medienbild vorstellbar, in dem z. B. das Programm nicht als Ursache, sondern als Folge von Rezipientenentscheidungen gesehen wird. Aber das Kausalmuster der starken Medien und der schwachen Massen erweist sich auch gegenüber kommunikationswissenschaftlichen Befunden als weitgehend resistent. Auf dieser Robustheit beruht die politisch relevante Stabilisierungsleistung der Orientierungsmuster - wissenschaftliche und politische Rationalität treten auseinander.

\footnotetext{
${ }^{78}$ In dieser Erklärungsvariante von Attribution wird retrospektiv von einem Phänomen auf Medien als Ursache geschlossen.

${ }^{79}$ In dieser Prognosevariante wird prospektiv von Veränderungen bei Medien auf Wirkungen für Politik, Wirtschaft, Erziehung usw. geschlossen.
} 


\section{Fazit: Medienpolitik im Spannungsfeld von Medien, Politik und Wissenschaft}

Der Analyse von Medienpolitik wurde ein Modell mit drei Dimensionen zugrundegelegt. Aus der Verknüpfung von verschiedenen Entscheidungsebenen, Medienbereichen und Interaktionsfeldern heraus kann Medienpolitik beschrieben und erklärt werden.

Medienpolitische Regulierung als der Kern von Medienpolitik ist eine Regelsetzung für die Beziehungen der Kommunikationsakteure. Diese Regeln fungieren als Restriktionen für das kommunikative Handeln; sie ermöglichen und schränken ein.

Regulierungen entstehen in und aus der Interaktion der medienpolitischen Akteure und sind somit aus der spezifischen Konstellation von Motiven, Kognitionen und Ressourcen erklärbar. In der deutschen Tradition gründen auch die rechtsförmigen Setzungen von Regeln in Übereinkommen, an deren Zustandekommen eine Vielzahl von Akteuren beteiligt wurden. Nicht nur aus dem hoheitlichen Charakter, sondern auch aus der Konsensbasis beziehen die Regulierungen die Autorität, die erforderlich ist, um ihnen die bindende Kraft zu geben.

Die Entwicklung der medienpolitischen Regulierung ist von drei langfristigen Verlagerungen des Schwerpunkts gekennzeichnet:

- von der Presse über den Rundfunk zum Netz;

- von politisch-publizistischen zu wirtschaftspolitischen Momenten;

- von staatlicher Steuerung zur Selbstregulation. ${ }^{80}$

Die einen Elemente nehmen - gemessen über die öffentliche Thematisierung und über die Regulierungsintensität - in ihrer medienpolitischen Bedeutung eher zu, die anderen eher ab. Dennoch bilden alle genannten Medienbereiche, Interaktionsfelder und Regulierungsformen weiterhin das Gesamt der Medienpolitik.

Regulierung als Ergebnis und als Prozeß ist ihrerseits Ausdruck von Restriktionen - sie steht in einem Ordnungsrahmen und ist geprägt von grundlegenden Orientierungsmustern. Jede Regulierung aktualisiert wiederum den Ordnungsrahmen und die Orientierungsmuster - bestätigt beides und schreibt beides fort. ${ }^{81}$

Letztlich ist somit die Medienpolitik in den grundlegenden kollektiven Schemata verankert. Damit besteht für die Wissenschaft nicht nur die Möglichkeit, durch empirische

\footnotetext{
${ }^{80}$ Die Regulierungsform ist nur implizit differenziert worden und hätte eine eigene Dimension mit den Ausprägungen „Staatliche Steuerung“ über „Kontextregulierung“ bis zu „Selbstregulation“ verdient.

${ }^{81}$ Eine Bewertung von Regulierung - z. B. im Hinblick auf die Effizienz oder die Qualität für die Bereitstellung von Medienangeboten - setzt den intermedialen, intertemporalen und internationalen Vergleich von Mediensystemen voraus, für den die empirische Grundlage fehlt.
} 
Erforschung der Ursachen und Wirkungen von Regulierung dazu beizutragen, politische Entscheidungen strategisch zu rationalisieren; vielmehr kann sie vor allem durch eine Prüfung der Medienwirkungshypothese ein Gegengewicht zu Alarmierung und Verharmlosung bilden. Das setzt voraus, dass sich die Forschung aus dem Paradigma der Makrofunktionen löst, ohne sich auf der Mikroebene einzelner Entscheidungen zu verlieren. Dies leistet der hier zugrunde liegende Public-Choice-Ansatz. Diese Perspektive erweist sich als außerordentlich fruchtbar: sie ermöglicht der Kommunikationswissenschaft die Entwicklung eines differenzierten medienpolitischen Analysemodells. Dies beinhaltet die Möglichkeit, auch die Entwicklung von Denkmustern - einschließlich ihrer wissenschaftlichen Komponenten und Varianten - aus der Interaktion der Akteure heraus zu erklären. Damit ist das Dual von „Medien und Politik“ zur Trias erweitert: Die Wissenschaft ist auch als Beobachter ein medienpolitischer Akteur und damit Teil des Modells. 


\section{Literatur}

Bausch, Hans (1980): Rundfunkpolitik nach 1945. Bd. I, II. München.

Bentele, Günter/Brosius, Hans-Bernd/Jarren, Otfried (Hrsg.) (2002): Öffentliche Kommunikation. Handbuch Kommunikations- und Medienwissenschaft. Wiesbaden.

Bizer, Kilian (1999): Anreizstrukturen der Akteure beim Kinder- und Jugendschutz in der Werbung. Darmstadt.

Bizer, Kilian (2000): Umweltpolitik und Gewaltenteilung - die Sonderabgabenrechtsprechung des Bundesverfassungsgerichts als Indiz für ein "Judikationsversagen"? In: Bizer, Kilian/Linscheidt, Bodo/Truger, Achim (Hrsg.). Staatshandeln im Umweltschutz. Berlin, 67-89.

Branahl, Udo (1992): Medienrecht. Eine Einführung. Opladen.

Braun, Dietmar (1999): Theorien rationalen Handelns in der Politikwissenschaft. Opladen.

Bruck, Peter A. (Hrsg.) (1993): Medienmanager Staat: Von den Versuchen des Staates, Medienvielfalt zu ermöglichen. Medienpolitik im internationalen Vergleich. München.

Bullinger, Martin (1999): Die Aufgaben des öffentlichen Rundfunks: Wege zu einem Funktionsauftrag. Gütersloh.

Coleman, James S. (1991): Grundlagen der Sozialtheorie. Band 1: Handlungen und Handlungssysteme. München.

Coleman, James S. (1992): Grundlagen der Sozialtheorie. Band 2: Körperschaften und die moderne Gesellschaft. München.

Diller, Ansgar (1980): Rundfunkpolitik im Dritten Reich. München.

Dörr, Dieter (2000): Europäische Medienordnung und -politik. In: Hans-BredowInstitut (Hrsg.): Internationales Handbuch für Hörfunk und Fernsehen 2000/2001. Baden-Baden, S. 65-88.

Downs, Anthony (1957): An Economic Theory of Democracy. New York.

Dröge, Franz/Kopper, Gerd G. (1991): Der Medien-Prozeß: zur Struktur innerer Errungenschaften der bürgerlichen Gesellschaft. Opladen.

Dussel, Konrad (1999): Deutsche Rundfunkgeschichte. Konstanz.

Eifert, Martin/Hoffmann-Riem, Wolfgang (1999): Die Entstehung und Ausgestaltung des dualen Rundfunksystems. In: Schwarzkopf, Dietrich (Hrsg.): Rundfunkpolitik in Deutschland. München, S. 50-116.

Eisermann, Jessica (2001): Mediengewalt. Wiesbaden.

Elster, Jon (1999): Wesen und Reichweite rationaler Handlungserklärung. In: Gosepath, Stefan (Hrsg.): Motive, Gründe, Zwecke. Frankfurt a. M., S. 57-75.

Engel, Christoph (1993): Privater Rundfunk vor der Europäischen Menschenrechtskonvention. Baden-Baden.

Esser, Hartmut (1999): Soziologie: Spezielle Grundlagen. Frankfurt a. M.

Fechner, Frank (2001): Medienrecht (2.Aufl.). Tübingen.

Fischer, Heinz-Dietrich (Hrsg.) (1991): Medienverbände in Deutschland. Geschichte, Berufsaspekte, Politik. Berlin. 
Franck, Georg (1998): Ökonomie der Aufmerksamkeit. Ein Entwurf. München, Wien. Frei, Norbert/Schmitz, Johannes (1989): Journalismus im Dritten Reich. München.

Frey, Bruno S./Kirchgässner, Gebhard (1994): Demokratische Wirtschaftspolitik (2. Aufl.). München.

Gellner, Winand (1990): Ordnungspolitik im Fernsehwesen: Bundesrepublik Deutschland und Großbritannien. Frankfurt a. M. u.a.

Glotz, Peter (1966): Demokratische Kommunikationspolitik in der entwickelten Industriegesellschaft. In: Hereth, Michael (Hrsg.): Junge Republik. Beiträge zur Mobilisierung der Demokratie. München, Wien, S. 75-102.

Grimm, Dieter (1995): Die Meinungsfreiheit in der Rechtsprechung des Bundesverfassungsgerichts. In: Neue Juristische Wochenschrift 48 (27): S. 1697-1704.

Grimm, Dieter (1999): Das Normziel Freiheit. In: epd Medien (65): S. 3-14.

Groebel, Jo/Hoffmann-Riem, Wolfgang/Köcher, Renate et al. (1995): Bericht zur Lage des Fernsehens. (2. Aufl.). Gütersloh.

Große Holforth, Dominik (2000): Medien, Aufmerksamkeit und politischer Wettbewerb. Berlin.

Grothe, Thorsten (2000): Restriktionen politischer Steuerung des Rundfunks. Wiesbaden.

Grothe, Thorsten/Schulz, Wolfgang (1994): Steuerungsperspektiven auf das duale Rundfunksystem. In: Holgersson, Silke/Jarren, Otfried/Schatz, Heribert (Hrsg.): Dualer Rundfunk in Deutschland. Münster, Hamburg, S. 63-78.

Heinrich, Herbert (1991): Deutsche Medienpolitik. Nauheim.

Heinrich, Jürgen (1994): Medienökonomie. Bd. 1: Mediensystem, Zeitung, Zeitschrift, Anzeigenblatt. Opladen.

Heinrich, Jürgen (1999): Medienökonomie. Bd. 2: Hörfunk und Fernsehen. Opladen, Wiesbaden.

Hellstern, Gerd-Michael/Hoffmann-Riem, Wolfgang/Reese, Jürgen et al. (1989): Rundfunkaufsicht. Bd.1: Rundfunkaufsicht in der Bundesrepublik Deutschland. Düsseldorf.

Herrmann, Günter (1994): Rundfunkrecht. München.

Hoffmann-Riem, Wolfgang (1989): Kommentar zu Art. 5 Abs. 1,2 GG. In: Wassermann, Rudolf (Hrsg.): Kommentar zum Grundgesetz für die Bundesrepublik Deutschland, Reihe Alternativkommentare, Bd. 1 (2. Aufl.). Neuwied u. a., S. 408-533.

Hoffmann-Riem, Wolfgang (1996): Regulating Media. Licensing and Supervision of Broadcasting in Six Countries. New York.

Hoffmann-Riem, Wolfgang (2000): Regulierung der dualen Rundfunkordnung. BadenBaden.

Hoffmann-Riem, Wolfgang/Schulz, Wolfgang/Held, Thorsten (2000): Konvergenz und Regulierung. Optionen für rechtliche Regelungen und Aufsichtsstrukturen im Bereich Information, Kommunikation und Medien. Baden-Baden.

Hofsähs, Rudolf (1994): Staatliche Informationstätigkeit. In: Schiwy, Peter/Schütz, Walter J. (Hrsg.): Medienrecht (3. Aufl.). Neuwied u. a., S. 395-400. 
Holgersson, Silke (1995): Fernsehen ohne Kontrolle. Zur Aufsichtspraxis der Landesmedienanstalt. Opladen.

Holtz-Bacha, Christina (1993): Presseförderung im westeuropäischen Vergleich. In: Bruck, Peter A. (Hrsg.): Medienmanager Staat. München, S. 443-567.

Holzer, Horst (1973): Kommunikationssoziologie. Reinbek.

Jarren, Otfried (1994): Medien- und Kommunikationspolitik in Deutschland. In: Jarren, Otfried (Hrsg.): Medien und Journalismus 1. Opladen, S. 107-143.

Jarren, Otfried (1996): Publizistische Märkte und Kommunikationspolitik. Öffentliche Regulierung statt politisch-administrativer Steuerung? In: Altmeppen, Klaus-Dieter (Hrsg.): Ökonomie der Medien und des Mediensystems. Opladen, S. 616-S.629.

Jarren, Otfried (1998): Medienpolitische Kommunikation. In: Jarren, Otfried/Sarcinelli, Ulrich/Saxer, Ulrich (Hrsg.): Politische Kommunikation in der demokratischen Gesellschaft. Opladen, S. 616-629.

Jarren, Otfried/Altmeppen, Klaus-Dieter/Schulz, Wolfgang (1993): Parteiintern - Medien und innerparteiliche Entscheidungsprozesse. In: Donsbach, Wolfgang/Jarren, Otfried/Kepplinger, Hans Mathias u.a. (Hrsg.): Beziehungsspiele - Medien und Politik in der öffentlichen Diskussion. Gütersloh, S. 111-157.

Jarren, Otfried/Donges, Patrick (2000): Medienregulierung durch die Gesellschaft Eine steuerungstheoretische und komparative Studie mit Schwerpunkt Schweiz. Wiesbaden.

Jarren, Otfried/Schulz, Wolfgang (1999): Rundfunkaufsicht zwischen Gemeinwohlsicherung und Wirtschaftsförderung. In: Schwarzkopf, Dietrich (Hrsg.): Rundfunkpolitik in Deutschland. München, S. 117-148.

Jürgens, Ekkehardt (1984): Deutsche Mediengeschichte. In: Modellversuch Journalisten-Weiterbildung (Hrsg.): Fernstudium Kommunikationswissenschaft. Bd. 1. München, 59-133.

Karrass, Fritz-Helmut (1994): Rundfunkfinanzrecht. In: Schiwy, Peter/Schütz, Walter J. (Hrsg.): Medienrecht. Neuwied u. a., S. 341-344.

Kepplinger, Hans Mathias (1982): Massenkommunikation: Rechtsgrundlagen, Medienstrukturen, Kommunikationspolitik. Stuttgart.

Kepplinger, Hans Mathias (1994): Kommunikationspolitik. In: Noelle-Neumann, Elisabeth/Schulz, Winfried/Wilke, Jürgen (Hrsg.): Fischer Lexikon Publizistik Massenkommunikation. Frankfurt a. M., S. 116-139.

Kiefer, Marie-Luise (2001): Medienökonomik: Einführung in eine ökonomische Theorie der Medien. München, Wien.

Kleinsteuber, Hans J. (1982): Rundfunkpolitik in der Bundesrepublik: der Kampf um die Macht über Hörfunk und Fernsehen. Opladen.

Kleinsteuber, Hans J. (1989): Massenmedien und Medienpolitik: Presse und Rundfunk als Thema der Politischen Wissenschaft. In: Bandemer, Stephan von/Wewer, Göttrik (Hrsg): Regierungssystem und Regierungslehre. Fragestellungen, Analysekonzepte, Forschungsstand. Opladen, S. 169-179.

Kleinsteuber, Hans J. (1993): Mediensysteme in vergleichender Perspektive. In: Rundfunk und Fernsehen 41 (3): S. 317-338.

Knoche, Manfred (1978): Einführung in die Pressekonzentrationsforschung. Berlin. 
Kopper, Gerd G. (1992): Medien- und Kommunikationspolitik der Bundesrepublik Deutschland: ein chronologisches Handbuch 1944 bis 1988. München u.a.

Kopper, Gerd G./Rager, Günter/Lehmann, Annette et al. (1993): Steuerungs- und Wirkungsmodelle. In: Bruck, Peter A. (Hrsg.): Medienmanager Staat. München, S. 35181.

Kops, Manfred (1999): Prinzipien zur Gestaltung von Rundfunkordnungen. In: Berg, Hans-Joachim (Hrsg.): Rundfunkgremien in Deutschland. Bd. 2. Berlin, S. 11-113.

Koszyk, Kurt (1966): Deutsche Presse im 19. Jahrhundert. Berlin.

Koszyk, Kurt (1972): Deutsche Presse 1914 - 1945. Berlin.

Kruse, Jörn (1996): Publizistische Vielfalt und Medienkonzentration zwischen Marktkräften und politischen Entscheidungen. In: Altmeppen, Klaus-Dieter (Hrsg.): Ökonomie der Medien und des Mediensystems. Opladen, S. 25-52.

Langenbucher, Wolfgang R. (1999): Rundfunk und Gesellschaft. In: Schwarzkopf, Dietrich (Hrsg.): Rundfunkpolitik in Deutschland. München, S. 149-315.

Latzer, Michael (1997): Mediamatik. Die Konvergenz von Telekommunikation, Computer und Rundfunk. Opladen.

Lerg, Winfried B. (1980): Rundfunkpolitik in der Weimarer Republik. München.

Löffler, Martin (1997): Presserecht (4. Aufl.). München.

Luhmann, Niklas (1975): Macht. Stuttgart.

Luhmann, Niklas (1996): Die Realität der Massenmedien. Opladen.

Luhmann, Niklas (2000): Die Politik der Gesellschaft. Frankfurt a. M.

Marcinkowski, Frank (1993): Publizistik als autopoietisches System: Politik und Massenmedien. Opladen.

Mettler-Meibom, Barbara (1986): Breitbandtechnologie. Opladen.

Meyn, Hermann (2001): Massenmedien in Deutschland. Berlin.

Morris, Merril/Ogan, Christine (1996): The Internet as a Mass Medium. In: Journal of Communication 46 (1): S. 39-50.

Mueller, Dennis C. (1997): Perspectives on Public Choice. Cambridge.

Mueller, Milton (2000): Technology and Institutional Innovation: Internet Domain Names. In: International Journal of Communications Law and Policy, 5 (1): S. 1-32.

Münch, Richard (1976): Theorie sozialer Systeme. Frankfurt a. M.

North, Douglas C. (1992): Institutionen, institutioneller Wandel und Wirtschaftsleistung. Tübingen.

Parsons, Talcott (1969): On the Concept of Political Power. Politics and Social Structure. New York.

Presse- und Informationsamt der Bundesregierung (Hrsg.) (1978): Bericht der Bundesregierung über die Lage von Presse und Rundfunk in der Bundesrepublik Deutschland (Medienbericht). Bonn.

Presse- und Informationsamt der Bundesregierung (Hrsg.) (1994): Bericht der Bundesregierung über die Lage der Medien in der Bundesrepublik Deutschland (Medienbericht 1994). Bonn. 
Presse- und Informationsamt der Bundesregierung (Hrsg.) (1998): Bericht der Bundesregierung über die Lage der Medien in der Bundesrepublik Deutschland 1998 (Medienbericht '98). Bonn.

Pürer, Heinz/Raabe, Johannes (1994): Medien in Deutschland. Bd. 1: Presse. München.

Ricker, Reinhart/Schiwy, Peter (1997): Rundfunkverfassungsrecht. München.

Roloff, Eckart Klaus (1994): Verbände und Organisationen im Medienbereich. In: Schiwy, Peter/Schütz, Walter J. (Hrsg.): Medienrecht. Neuwied u.a., S. 439-457.

Ronneberger, Franz (1978): Kommunikationspolitik. Teil I: Institutionen, Prozesse, Ziele. Mainz.

Ronneberger, Franz (1980): Kommunikationspolitik. Teil II: Kommunikationspolitik als Gesellschaftspolitik. Mainz.

Ronneberger, Franz (1986): Kommunikationspolitik. Teil III: Kommunikationspolitik als Medienpolitik. Mainz.

Ronneberger, Franz (1989): Die Rolle der Verfassungsgerichtsbarkeit beim Wandel des Rundfunksystems. In: Kaase, Max/Schulz, Winfried (Hrsg.): Massenkommunikation. Opladen, S. 72-84.

Ronneberger, Franz (1995): Theorie der Kommunikationspolitik. In: Burkart, Roland/Hömberg, Walter (Hrsg.): Kommunikationstheorien (2. Aufl.). Wien, S. 191-203.

Rowley, Charles K. (Hrsg.) (1993a): Public Choice Theory Volume I. Homo Economicus in the Political Market Place. Aldershot, Bookfield.

Rowley, Charles K. (Hrsg.) (1993b): Public Choice Theory Volume II. The Characteristics of Political Equilibrium. Aldershot, Bookfield.

Rowley, Charles K. (Hrsg.) (1993c): Public Choice Theory Volume III. The Separation of Powers and Constitutional Political Economy. Aldershot, Bookfield.

Rühl, Manfred (1973): Politik und öffentliche Kommunikation. Auf dem Wege zu einer Theorie der Kommunikationspolitik. In: Publizistik 18 (1): S. 5-25.

Rühl, Manfred (1985): Kommunikationspolitik in der Entwicklung zu einem wissenschaftlichen Spezialgebiet. In: Schreiber, Erhard/Langenbucher, Wolfgang R./Hömberg, Walter (Hrsg.): Kommunikation im Wandel der Gesellschaft. Düsseldorf, S. 303-312.

Rühl, Manfred (1993): Marktpublizistik. Oder: Wie alle - reihum - Presse und Rundfunk bezahlen. In: Publizistik 38 (2): S. 125-152.

Saxer, Ulrich (1986): Systematische Kommunikationspolitik. In: Langenbucher, Wolfgang R. (Hrsg.): Publizistik- und Kommunikationswissenschaft. Wien, S. 148-159.

Saxer, Ulrich (1994): Konstituenten wissenschaftlicher Kommunikationspolitik. In: Bentele, Günter/Hesse, Kurt R. (Hrsg.): Publizistik in der Gesellschaft. Konstanz, S. 1550.

Scharpf, Fritz W. (2000): Interaktionsformen. Akteurzentrierter Institutionalismus in der Politikforschung. Opladen.

Schatz, Heribert/Habig, Christopher/Immer, Nikolaus (1990): Medienpolitik. In: Beyme, Klaus von/Schmidt, Manfred G. (Hrsg.): Politik in der Bundesrepublik Deutschland. Opladen, S. 331-359. 
Schatz, Heribert/Lange, Klaus (1982): Massenkommunikation und Politik. Frankfurt a.M.

Schellhaaß, Horst M. (1994): Sicherung der Rundfunkfreiheit - Eine ökonomische Interpretation der Fernsehurteile. In: Jahrbuch für Sozialwissenschaften 45 (2): S. 228244.

Scherer, Joachim (1985): Telekommunikationsrecht und Telekommunikationspolitik. Baden-Baden.

Schimank, Uwe (1996): Theorien gesellschaftlicher Differenzierung. Opladen.

Schneider, Volker (1999): Staat und technische Kommunikation. Die politische Entwicklung der Telekommunikation in den USA, Japan, Großbritannien, Deutschland, Frankreich und Italien. Opladen, Wiesbaden.

Schramm, Wilbur/Siebert S, Fred/Peterson, Theodore (1956): Four Theories of the Press. Urbana.

Schulz, Wolfgang (1996): Recht im Widerstreit. Regulierung der Medienwirtschaft durch Recht. In: Altmeppen, Klaus-Dieter (Hrsg.): Ökonomie der Medien und des Mediensystems. Opladen, S. 221-236.

Schulz, Wolfgang (1997): Regulierung von Medien- und Telediensten. Köln.

Schütz, Walter J. (Hrsg.) (1999): Medienpolitik: Dokumentation der Kommunikationspolitik in der Bundesrepublik Deutschland von 1945 - 1990. Konstanz.

Sen, Amartya K. (1999): Rationale Trottel: Eine Kritik der behavioristischen Grundlagen der Wirtschaftstheorie. In: Gosepath, Stefan (Hrsg.): Motive, Gründe, Zwecke. Frankfurt a. M., S. 76-102.

Stigler, George J. (1975): The Citizen and the State. Essays on Regulation. Chicago, London.

Stöber, Rudolf (2000): Deutsche Pressegeschichte. Konstanz.

Stuiber, Heinz-Werner (1998): Medien in Deutschland. Bd. 2: Rundfunk. Konstanz.

Theis-Berglmair, Anna Maria (1997): Das demokratische Element der Ungewißheit. In: Schatz, Heribert/Jarren, Otfried/Knaup, Bettina (Hrsg.): Machtkonzentration in der Multimediagesellschaft? Opladen, 25-33.

Tonnemacher, Jan (1996): Kommunikationspolitik in Deutschland: Eine Einführung. Konstanz.

Vesting, Thomas (1997): Prozedurales Rundfunkrecht. Baden-Baden.

Vowe, Gerhard (1997): Medienpolitik im Spannungsfeld von staatlicher Steuerung und Regulierung. Das Beispiel der "Freiwilligen Selbstkontrolle Fernsehen". In: Schatz, Heribert/Jarren, Otfried/Knaup, Bettina (Hrsg.): Machtkonzentration in der Multimediagesellschaft? Opladen, 216-243.

Vowe, Gerhard (1999): Medienpolitik zwischen Freiheit, Gleichheit und Sicherheit. In: Publizistik 44 (4): S. 395-415.

Weizsäcker, Carl Christian v. (1982): Staatliche Regulierung - positive und normative Theorie. In: Schweizerische Zeitschrift für Volkswirtschaft und Statistik 118 (3): S. 325-343. 
Werle, Raymund (1996): Verbände im Politikfeld Multimedia - Akteure, Rollen, Aufgaben. In: Kubicek, Herbert/Müller, Günter/Raubold, Eckart et al. (Hrsg.). Neue Spieler - Neue Regeln. Jahrbuch Telekommunikation und Gesellschaft Bd. 4. Heidelberg, 201216.

Wiek, Ulrich (1996): Politische Kommunikation und Public Relations in der Rundfunkpolitik. Berlin.

Wilhelm, Bernhard (1994): Medienpolitik. In: Schiwy, Peter/Schütz, Walter J. (Hrsg.): Medienrecht (3. Aufl.). Neuwied u.a., S. 228-234.

Wilke, Jürgen (Hrsg.) (1999): Mediengeschichte der Bundesrepublik Deutschland. Köln u. a.

Wilke, Jürgen (2000): Grundzüge der Medien- und Kommunikationsgeschichte: Von den Anfängen bis ins 20. Jahrhundert. Köln u. a.

Williamson, Oliver E. (1990): Die ökonomischen Institutionen des Kapitalismus. Tübingen.

Witte, Eberhard (1982): Ziele deutscher Medienpolitik. München, Wien.

Zerdick, Axel/Picot, Arnold/Schrape, Klaus et al. (1999): Die Internet-Ökonomie. Strategien für die digitale Wirtschaft. Berlin u.a. 